\title{
Earthworm extract attenuates silica-induced pulmonary fibrosis through Nrf2-dependent mechanisms
}

\author{
Jingjin Yang ${ }^{1,3}$, Ting Wang ${ }^{2,3}$, Yan $\mathrm{Li}^{1}$, Wenxi Yao ${ }^{1}$, Xiaoming $\mathrm{Ji}^{1}$, Qiuyun Wu${ }^{1}$, Lei Han ${ }^{1}$, Ruhui Han ${ }^{1}$, Weiwen Yan ${ }^{1}$,
} Jiali Yuan ${ }^{1}$ and Chunhui $\mathrm{Ni}^{1}$

Silicosis is an occupational pulmonary fibrosis caused by inhalation of silica $\left(\mathrm{SiO}_{2}\right)$ and there are no ideal drugs to treat this disease. Earthworm extract (EE), a natural nutrient, has been reported to have anti-inflammatory, antioxidant, and anti-apoptosis effects. The purpose of the current study was to test the protective effects of $\mathrm{EE}$ against $\mathrm{SiO}_{2}$-induced pulmonary fibrosis and to explore the underlying mechanisms using both in vivo and in vitro models. We found that treatment with EE significantly reduced lung inflammation and fibrosis and improved lung structure and function in $\mathrm{SiO}_{2}$-instilled mice. Further mechanistic investigations revealed that $\mathrm{EE}$ administration markedly inhibited $\mathrm{SiO}_{2}$-induced oxidative stress, mitochondrial apoptotic pathway, and epithelial-mesenchymal transition in HBE and A549 cells.

Furthermore, we demonstrate that $\mathrm{Nrf2}$ activation partly mediates the interventional effects of $\mathrm{EE}$ against $\mathrm{SiO}_{2}$-induced pulmonary fibrosis. Our study has identified EE to be a potential anti-oxidative, anti-inflammatory, and anti-fibrotic drug for silicosis.

Laboratory Investigation (2016) 96, 1279-1300; doi:10.1038/labinvest.2016.101; published online 24 October 2016

Silicosis is a kind of occupational pneumoconiosis caused by inhalation of silica $\left(\mathrm{SiO}_{2}\right)$ particles, which can trigger a persistent inflammatory cascade that leads to progressive lung fibrosis and subsequent respiratory failure due to deterioration of lung function and reduction in gas exchange area. The incidence and prevalence of silicosis has been increasing, particularly in developing countries such as China and India. ${ }^{1,2}$ Data from the official website of the Ministry of Health of China showed that 26873 new cases were diagnosed with pneumoconiosis in 2014, accounting for $89.66 \%$ of all reported occupational diseases in China, of which 11471 (42.69\%) were silicosis. Although therapy for silicosis includes a variety of drugs and non-pharmacological interventions, there is still an urgent need developing new and efficient approaches as none of current therapies can inhibit disease progression or reverse lung fibrosis effectively.

Accumulating studies over the past several decades have identified many important pathogenic mechanisms that promote silicosis, ${ }^{3}$ and oxidative stress is one crucial molecular mechanism modulating multiple signaling pathways and biological processes. ${ }^{4}$ Exposure to crystalline $\mathrm{SiO}_{2}$ results in the generation of reactive oxygen species (ROS) by $\mathrm{SiO}_{2}$ particles or $\mathrm{SiO}_{2}$-activated cells, ${ }^{5}$ at the levels of exceeding the capacity of pulmonary antioxidant defense. Oxidative stress can drive aberrant epithelial cell phenotypic changes, including increased cytokines expression, epithelialmesenchymal transition (EMT), and apoptosis. ${ }^{6,7}$ To counteract oxidative stress, lung cells enlist a battery of classical antioxidant systems, such as superoxide dismutase (SOD), glutathione (GSH), and especially Phase II enzymes including $\mathrm{NADPH}$ quinone oxidoreductase-1 (NQO-1) and Heme oxygenase-1 (HO-1). ${ }^{8-10}$ As a crucial transcriptional factor, nuclear factor erythroid 2-related factor 2 (Nrf2) is an orchestrator of the induction of these antioxidants. ${ }^{11}$

Natural products have established a strong position in drug research and development. Nonetheless, their underlying mechanisms are still unknown, which hampers drug discovery. The earthworm is traditionally used as a functional food component for the intervention of various diseases and health promotion. Extracting and using biologically active compounds from earthworms have been practiced by indigenous people throughout the world, more particularly in Asia, including India, China, and Vietnam. In 1983, Mihara

\footnotetext{
Department of Occupational Medicine and Environmental Health and Key Laboratory of Modern Toxicology of Ministry of Education, School of Public Health, Nanjing Medical University, Nanjing, China and ${ }^{2}$ Department of Pathology, The Affiliated Drum Tower Hospital, Nanjing University Medical School, Nanjing, China Correspondence: Professor C Ni, Department of Occupational Medicine and Environmental Health and Key Laboratory of Modern Toxicology of Ministry of Education, School of Public Health, Nanjing Medical University, 818 East Tianyuan Road, Nanjing 211166, China. 
et $a l^{12}$ isolated six types of proteolytic enzymes from the earthworm extract (EE). These enzymes are jointly termed lumbrokinase or earthworm fibrinolytic enzyme, and they are the main active components of EE. Lumbrokinase can dissolve the fibrin itself or convert plasminogen to plasmin by inducing endogenous tissue plasminogen activator activity to dissolve fibrin. ${ }^{13}$ In addition to anticoagulation and fibrinolytic activity, ${ }^{12}$ multiple biological functions have been ascribed to $\mathrm{EE}$, including anti-inflammatory, ${ }^{14,15}$ antioxidant, ${ }^{14,16}$ and anti-apoptosis ${ }^{17-20}$ activities.

Herein, we hypothesize that EE exerts its pharmacological regulative effects towards $\mathrm{SiO}_{2}$-induced pulmonary fibrosis via Nrf2-dependent inhibition of oxidative stress and subsequently epithelial injury responses including EMT and apoptosis in vivo and in vitro. As far as we know, it is the first study on the protective effects of EE against silicosis and the first time to elucidate its potential underlying mechanisms.

\section{MATERIALS AND METHODS}

\section{Animals}

Pathogen-free male C57BL/6 mice at 4-6 weeks of age, weighing 20-25g, were purchased (SLAC, Shanghai, China). All animals were kept in a temperature- and light-controlled environment with a 12-h light/12-h dark cycle and used after an acclimatization period of 1 week. The study was approved by the Institutional Animal Care and Use Committee of Nanjing Medical University and conducted according to the national and institutional rules regarding animal experiments.

\section{Tested Drug}

The EE lyophilized powder used in this study was obtained from Shanxi ZhongYuanWei Pharmaceutical Company. The fibrinolytic activity of $\mathrm{EE}$, which mainly attributes to lumbrokinase, is $200000 \mathrm{U} / \mathrm{mg}$ and offers the basis for administered dosage. The urokinase-fibrin plate method was used for the fibrinolytic activity determination of EE. Briefly, the agarose, bovine fibrinogen, bovine thrombin were mixed in a certain proportion to produce a fibrin plate. $10 \mu \mathrm{l}$ per sample urokinase standards in different concentrations and EE samples $(0.01 \mathrm{mg} / \mathrm{ml})$ were pointed on the fibrin plate and put in an incubator at $37^{\circ} \mathrm{C}$ for $18 \mathrm{~h}$. The vertical diameters of fibrinolytic circle were measured (Supplementary Figure 1A; Supplementary Table 1) and the standard linear regression equation was calculated by the denary logarithm of urokinase standard units (X) and the denary logarithm of product of vertical diameters (Y) (Supplementary Table 1; Supplementary Figure 1B). The fibrinolytic activity of EE was calculated based on the standard linear regression equation (EE's product of fibrinolytic circle is $1.69 \mathrm{~cm}^{2}$ ).

$\mathrm{EE}$ was dissolved with saline before use for all in vivo experiments or phosphate-buffered saline (PBS) for our in vitro tests. In addition, $\mathrm{N}$-acetylcysteine (NAC), a precursor for intracellular GSH synthesis with the potent effects against oxidative stress, was purchased from Sigma-Aldrich
(St. Louis, MO, USA) and used as the positive control in our in vitro experiments.

\section{Silica-Induced Pulmonary Fibrosis Murine Model and Experimental Design}

Male C57BL/6 mice $(n=54)$ were randomly assigned to sham control group (sham), model group (silicosis), and EE-treated group (EE) ( $n=18$ in each group). The silicosis group and EE group were anesthetized by intraperitoneal injection of pentobarbital followed by a single intratracheal instillation of $50 \mu \mathrm{l} \mathrm{SiO}{ }_{2}$ suspension $(50 \mathrm{~g} / \mathrm{l})$. The sham group had only $50 \mu \mathrm{l}$ saline administered. Thereafter, the EE group received $600 \mathrm{U} \mathrm{EE}(1500 \mathrm{U} / \mathrm{ml}, 0.4 \mathrm{ml})$ by intraperitoneal injection once a day, whereas the other groups had $0.4 \mathrm{ml}$ saline injected. Six mice from each group were sacrificed on days 7 , 14 , and 28.

\section{Histopathological Examination of the Lungs}

To evaluate the histopathological changes, the left lower pulmonary lobe from the sacrificed mice was harvested and flushed with PBS to remove blood. Then, the lung was fixed in $10 \%$ neutral-buffered formalin for $24 \mathrm{~h}$, embedded in paraffin wax, and sectioned $(6 \mu \mathrm{m})$. Subsequently, paraffin sections were stained with hematoxylin and eosin. The pathological sections were evaluated under a light microscope in a random order and in a blinded fashion by two independent, experienced pathologists. The structural alterations of tissue were assessed based on the degree of cellular proliferation, alveolar wall thickening, inflammatory lesions, and collagen deposition or fibrosis. These changes were graded in terms of severity and distribution and scored by a grading system as described previously. ${ }^{21}$

\section{Bronchoalveolar Lavage Fluid}

For evaluating the changes in terms of inflammatory cells in the lungs, bronchoalveolar lavage was conducted and the fluid was examined. The bronchoalveolar lavage procedure was conducted on days 7,14 , and 28 after $\mathrm{SiO}_{2}$ instillation. In brief, the trachea was exposed and cannulated with a 20 -gauge catheter. After instillation of $0.6 \mathrm{ml}$ sterile PBS three times through the trachea into the lung, bronchoalveolar lavage fluid (BALF) was recovered at $75-90 \%$ of the original volume. The total number of cells in BALF was counted on a hemocytometer. Then BALF was spun onto cytocentrifuge slides using cytospin for $5 \mathrm{~min}$ at 800 r.p.m. and routinely with WrightGiemsa staining. The number of macrophages, neutrophils, and lymphocytes in 400 cells was calculated according to morphology on randomly selected sections of the slide. ${ }^{22}$

\section{Micro-Computed Tomography Imaging and Image Analysis}

To evaluate lung fibrosis in vivo, we conducted automated micro-computed tomography (micro-CT). After mice were anesthetized with intraperitoneally administered thiopental sodium, the mice were scanned in supine position using a 
desktop in vivo small animal micro-CT (SkyScan 1076, software version 3.2, Kontich, Belgium) on 28 days after induction. The length of a complete respiratory cycle was divided into four phases of identical length, corresponding to four phases of the respiratory cycle, from the initiation of inspiration to end-expiration. In the image analysis stage, only the images acquired in the end-expiration projection were used as evaluation of air trapping and were not influenced by anesthesia-induced gasping. On visual inspection of reconstructed images in Dataviewer (SkyScan) of lung regions directly above the diaphragm in inspiration and expiration, the discriminating threshold for air was set at $-383 \mathrm{HU}$ to capture the inflation of lungs on inspiration. Total segmentation time was $10 \mathrm{~min}$ per scan and required no interference from the investigator. ${ }^{23}$

\section{Cell Culture and Ttreatment}

Human bronchial epithelial (HBE) and human lung adenocarcinoma A549 cells were purchased from American Type Culture Collection (ATCC, Manassas, VA, USA) and were grown in Dulbecco's modified Eagle's medium (DMEM; GIBCO, Invitrogen, Carlsbad, CA, USA) supplemented with $10 \%$ fetal bovine serum (ScienCell, San Diego, CA, USA), $100 \mathrm{U} / \mathrm{ml}$ of penicillin, $100 \mathrm{mg} / \mathrm{ml}$ of streptomycin in a humidified incubator at $37^{\circ} \mathrm{C}$ in an atmosphere of $5 \% \mathrm{CO}_{2}$ and $95 \%$ air. A549 cell line is often regarded as human type II alveolar epithelial (AT II) cell in the study of pulmonary fibrosis though it belongs to cancer cells.

HBE and A549 cells were divided into the following six treatment groups: control, $\mathrm{SiO}_{2} 200 \mu \mathrm{g} / \mathrm{ml} ; \mathrm{SiO}_{2} 200 \mu \mathrm{g} / \mathrm{ml}$ +EE $1 \mathrm{U} / \mu \mathrm{l} ; \mathrm{SiO}_{2} 200 \mu \mathrm{g} / \mathrm{ml}+\mathrm{EE} 2 \mathrm{U} / \mu \mathrm{l} ; \mathrm{SiO}_{2} 200 \mu \mathrm{g} / \mathrm{ml}+\mathrm{NAC}$ $0.1 \mathrm{mM}$; and $\mathrm{SiO}_{2} 200 \mu \mathrm{g} / \mathrm{ml}+\mathrm{NAC} 1 \mathrm{mM}$. Cells were cotreated by $\mathrm{SiO}_{2}$ together with $\mathrm{EE}, \mathrm{NAC}$ or vehicle (PBS) for $24 \mathrm{~h}$.

For Nrf2 small interfering (si) RNA experiment, HBE and A549 cells were divided into six groups: control siRNA; control siRNA $+\mathrm{SiO}_{2} 200 \mu \mathrm{g} / \mathrm{ml}$; control siRNA $+\mathrm{SiO}_{2} 200 \mu \mathrm{g} /$ $\mathrm{ml}+\mathrm{EE} 2 \mathrm{U} / \mu \mathrm{l} ; \mathrm{Nrf} 2$ siRNA; Nrf2 siRNA+SiO $2200 \mu \mathrm{g} / \mathrm{ml}$; $\mathrm{Nrf2}$ siRNA+SiO $200 \mu \mathrm{g} / \mathrm{ml}+\mathrm{EE} 2 \mathrm{U} / \mu \mathrm{l}$. Prior to $\mathrm{SiO}_{2}$ stimulation, cells were transfected with Nrf2 siRNA or control siRNA for $48 \mathrm{~h}$. After incubation, cells were exposed to $\mathrm{SiO}_{2}$ combined with EE or NAC of corresponding dose for $24 \mathrm{~h}$.

\section{Cell Viability Assay}

The effects of EE on the viability of HBE and A549 cells were determined using Cell Counting Kit 8 (CCK8) assay (Beyotime, Shanghai, China). Briefly, 5000 cells per well were plated in 96-well plates in a final volume of $100 \mu \mathrm{l}$. After overnight incubation, the cells were treated with varying concentrations of EE $(1-4 \mathrm{U} / \mu \mathrm{l})$ or NAC $(0.1-10 \mathrm{mM})$ with or without $\mathrm{SiO}_{2}$ stimulation for 12, 24, or $48 \mathrm{~h}$, respectively. Thereafter, cells were incubated in $10 \%$ CCK8 solution that was diluted in normal culture medium for $1 \mathrm{~h}$ at $37^{\circ} \mathrm{C}$. The absorbance was then recorded at $450 \mathrm{~nm}$ and $650 \mathrm{~nm}$ (absorbance $450 \mathrm{~nm}$, reference $650 \mathrm{~nm}$ ) using an automatic micro-plate reader (TECAN Infinite M200, Männedorf, Switzerland). The net $\mathrm{A}_{450 \mathrm{~nm}}-\mathrm{A}_{650 \mathrm{~nm}}$ was taken as the index of cell viability. The percent viability of the treated cells was calculated by the formula: $\%$ viability $=\left(\mathrm{A}_{450 \mathrm{~nm}}-\mathrm{A}_{650 \mathrm{~nm}}\right)$ treated $/\left(\mathrm{A}_{450 \mathrm{~nm}}-\mathrm{A}_{650 \mathrm{~nm}}\right)_{\text {control }} \times 100 \%$. All experiments were performed in triplicate and repeated independently three times.

\section{Hoechst 33258 Staining}

Morphological changes of cell nuclei were assessed by Hoechst 33258 Staining Kit (Beyotime, Shanghai, China). HBE and A549 cells were seeded at a density of $3 \times 10^{5}$ cells per well into 12-well plates for $24 \mathrm{~h}$ and treated as described above for $24 \mathrm{~h}$. After treatment, cells were washed with PBS and fixed with $4 \%$ paraformaldehyde at room temperature for 15 min, and then the cells were washed with PBS again and stained with Hoechst 33258 staining solution for $5 \mathrm{~min}$ at room temperature. The stained nuclei were observed using an inversion fluorescence microscope (Nikon, Tokyo, Japan) and the images were recorded for later analysis. The fluorescence intensity was quantified using Image J software (NIH, USA). The morphological features of apoptosis were evident, including chromatin condensation, nuclear fragmentation and apoptotic body formation. All experiments were repeated independently three times.

\section{Intracellular ROS Measurement}

The intracellular ROS was detected by ROS Assay Kit (Beyotime, Shanghai, China), using an oxidation-sensitive fluorescent probe DCFH-DA. DCFH-DA enters cells passively and is converted into non-fluorescent DCFH, which reacts with ROS to form the fluorescent product DCF. HBE and A549 cells were plated at a density of $3 \times 10^{5}$ cells per well in 12 -well plates overnight and treated as described above. After stimulation for $24 \mathrm{~h}$, the medium was removed and the cells were incubated with DCFH-DA $(10 \mu \mathrm{M})$ diluted with serumfree medium for $30 \mathrm{~min}$ at $37^{\circ} \mathrm{C}$ in the dark. After incubation, the cells were washed three times with PBS. Then, representative images were taken by an inversion fluorescence microscope (Nikon, Tokyo, Japan). The intensity of fluorescence staining was quantified with Image J software $(\mathrm{NIH}$, USA). All experiments were repeated independently three times.

\section{SOD, MDA, and GSH Assay}

Standing the whole blood of mice for $3 \mathrm{~h}$ and the blood was centrifuged for serum collection. HBE and A549 cells were plated at a density of $7.5 \times 10^{5}$ cells per well in 6-well plates overnight and treated as described above. HBE and A549 cells lysates were centrifuged for supernatant collection. The enzyme activities of total SOD, malonaldehyde (MDA) and GSH were determined in the serum and supernatant. SOD, $\mathrm{MDA}$, and GSH assays were performed according to the manufacturer's instructions (Beyotime, Shanghai, China). 
SOD activity was determined as the inhibition of the reduction of nitrol blue tetrazolium in the sample at $550 \mathrm{~nm}$. MDA levels were analyzed with 2-thiobarbituric acid. GSH levels were measured using the DTNB-GSSG reductase recycling assay. All of the assays used colorimetric methods based on biochemical reactions, and the results were calculated using the absorbance values of the samples and standard equations. All experiments were performed in triplicate and repeated independently three times.

\section{MMP Assay}

Changes in mitochondrial membrane potential (MMP) were assessed by MMP assay kit with J-aggregate-forming lipophilic cationic probe, 5,5',6,6'-tetrachloro-1,1',3,3'-tetraethyl benzimidazol carbocyanine iodide (JC-1; Beyotime, Shanghai, China). In healthy cells, JC-1 accumulates in the mitochondria as JC-1 aggregates (whose fluorescence is red) and also in the cytoplasm as JC-1 monomers (whose fluorescence is green). During early apoptosis, the MMP collapses. As a result, JC-1 aggregates cannot accumulate within the mitochondria and dissipate into JC-1 monomers leading to loss of red fluorescence. Therefore, collapse of the MMP is signified by decrease in the ratio of red to green fluorescence. HBE and A549 cells were plated at a density of $3 \times 10^{5}$ cells per well in 12-well plates overnight and treated as described above. Cells were washed with PBS and incubated with the medium containing $20 \mu \mathrm{g} / \mathrm{ml} \mathrm{JC-1} \mathrm{staining} \mathrm{working} \mathrm{solution}$ at $37^{\circ} \mathrm{C}$ for $20 \mathrm{~min}$ and washed three times with JC-1 staining buffer. The fluorescence images were observed using an inversion fluorescence microscope (Nikon, Tokyo, Japan) and the typical photographs were captured.

\section{ATP Content Assay}

The firefly-luciferase-based ATP Assay Kit (Beyotime, Shanghai, China) was used to detect the ATP content in the HBE and A549 cells according to the manufacturer's protocol. HBE and A549 cells were seeded at a density of $7.5 \times 10^{5}$ cells per well into the 6-well plates overnight and treated as described above. Cells were collected after washing in PBS and lysed in $200 \mu$ l of ATP assay lysis buffer. The lysates were centrifuged at $15000 \mathrm{~g}$ for $5 \mathrm{~min}$ at $4{ }^{\circ} \mathrm{C}$ and the supernatant was collected. Then, $20 \mu \mathrm{l}$ supernatant per sample were added to a 96-well plate containing $100 \mu \mathrm{l}$ per well ATP detection working solution. Fluorescence was measured using a chemiluminescence Detector (Tecan Infinite 200 PRO, Männedorf, Switzerland). The ATP content was calculated from the standard curve. All experiments were performed in triplicate and repeated independently three times.

\section{Immunofluorescence Assay of Nrf2}

HBE and A549 cells were grown on cover slips overnight and treated as described above. After a series of brief washes with PBS, cells were fixed in methanol for $15 \mathrm{~min}$. After washing with PBS with Tween 20 for three times, the fixed cells were incubated with $5 \%$ bovine serum albumin at room temperature for $1 \mathrm{~h}$. Subsequently, Nrf2 antibody (1:100 dilution; Abcam, Cambridge, UK) was added and incubated with cells at $4{ }^{\circ} \mathrm{C}$ overnight. Then, cells were washed with PBS with Tween 20 and incubated with fluorescein isothiocyanate-labeled goat anti-rabbit secondary antibody (Beyotime, Shanghai, China) at room temperature for $1 \mathrm{~h}$. Cells were then counterstained with 4', 6-diamidino-2phenylindole (Beyotime, Shanghai, China). Fluorescence images were obtained with an inversion fluorescence microscope (Nikon, Tokyo, Japan) and the typical photographs were captured.

\section{Quantitative Real-Time Polymerase Chain Reaction Assay}

Total RNA was extracted from HBE and A549 cells with TRIzol reagent (Invitrogen, Carlsbad, CA, USA) according to the manufacturer's instructions. RNA $(1 \mu \mathrm{g})$ was reversetranscribed using a PrimeScript RT reagent Kit (TaKaRa, Ostu, Japan) in a thermal cycler PCR system (Bio-Rad, Hercules, CA, USA). The reaction conditions included $42{ }^{\circ} \mathrm{C}$ for $60 \mathrm{~min}, 70^{\circ} \mathrm{C}$ for $5 \mathrm{~min}$, and $4{ }^{\circ} \mathrm{C}$ for $\infty$. Our gene-specific primers for mice or human NQO-1, HO-1 and GAPDH are listed in Supplementary Table 2. Gene expression was assessed by real-time PCR (ABI 7900 Real-Time PCR System, Applied Biosystems, Foster City, CA, USA) with SYBR Premix Ex TaqII (Tli RNaseH Plus) (TaKaRa, Ostu, Japan). With a hot start $\left(15 \mathrm{~min}\right.$ at $\left.95^{\circ} \mathrm{C}\right)$, the amplification protocol consists of denaturation for $15 \mathrm{~s}$ at $95^{\circ} \mathrm{C}$, annealing for $5 \mathrm{~s}$ at $60^{\circ} \mathrm{C}$ and extension for $10 \mathrm{~s}$ at $72^{\circ} \mathrm{C}$ for 40 cycles. A final dissociation stage was run to generate a melting curve for verification of amplification product specificity. Each sample was assayed at least three times from the same RNA. Data were collected and processed with SDS 2.4 software (Applied Biosystems, Foster City, CA, USA) and given as threshold cycle $(\mathrm{Ct})$ values. GAPDH was used as a housekeeping gene for normalization. The fold increase in mRNA expression compared with the control cells was determined using the $2^{-\Delta \Delta \mathrm{Ct}}$ method.

\section{siRNA Transfection}

The silencing of Nrf2 in HBE and A549 cells was carried out by using Nrf2 siRNA (Ribobio, Guangzhou, China) according to the manufacturer's instructions. Cells were seeded at a density of $7.5 \times 10^{5}$ cells per well into a 6-well plate and incubated overnight. Medium containing Nrf2 siRNA, or control siRNA was mixed with riboFECT CP Reagent (Ribobio, Guangzhou, China) for $20 \mathrm{~min}$ at room temperature and then added to the cells. The final concentration of siRNA was $50 \mathrm{nM}$ and the mixture was incubated for $48 \mathrm{~h}$. Gene silencing was measured by western blotting.

\section{Western Blotting Assay}

Total protein samples were extracted from lung tissues and HBE and A549 cells using an appropriate cold lysis buffer supplemented with $1 \mathrm{mM}$ phenylmethylsulfonyl fluoride, and the protein concentration was determined using a BCA 

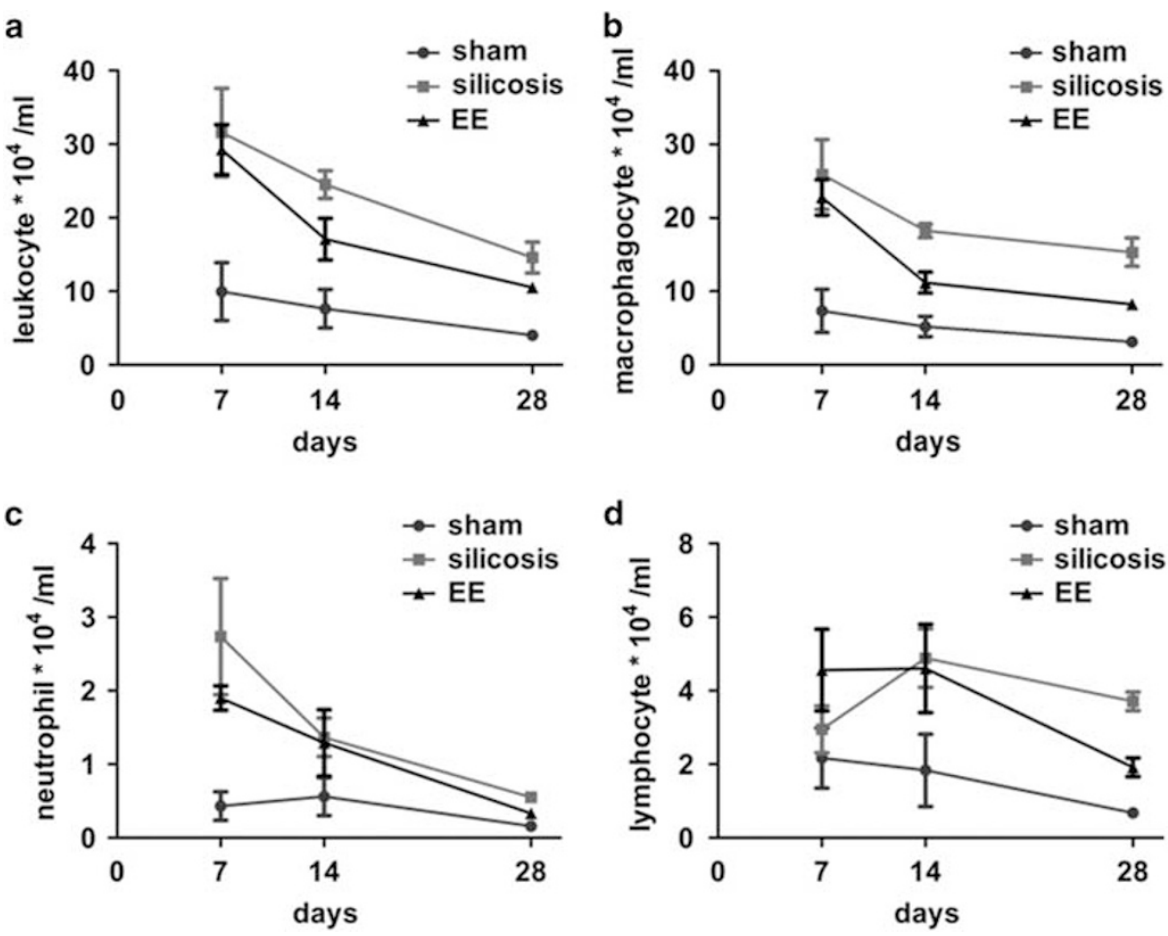

Figure $1 \mathrm{EE}$ attenuates $\mathrm{SiO}_{2}$-induced total and differential cell counts in BALF. Animals and treatments are as described under Materials and Methods. The total cell count (a) and the number of macrophages (b), neutrophils (c), and lymphocytes (d) in BALF were determined by the examination of cytocentrifuge slides and using a hemocytometer. Data are expressed as mean \pm SD $(n=6)$.

protein assay kit (Beyotime, Shanghai, China). Samples were subjected to the SDS-PAGE (10-15\%) and transferred onto a PVDF membrane $(0.22 \mu \mathrm{m}$ pore size, Millipore, Bedford, MA, USA). Membranes were blocked in $5 \%$ nonfat milk in Trisbuffered saline containing $0.1 \%$ Tween 20 (TBST; $50 \mathrm{mM}$ Tris- $\mathrm{HCl}(\mathrm{pH}=7.6), 150 \mathrm{mM} \mathrm{NaCl}, 0.1 \%$ Tween 20$)$ at room temperature for $1 \mathrm{~h}$ and incubated overnight at $4{ }^{\circ} \mathrm{C}$ with the primary antibodies against transforming growth factor- $\beta 1$ (TGF- $\beta 1$ ), interleukin-1 $\beta$ (IL-1 $\beta$ ), Bcl-2 (1:200 dilution; Santa Cruz Biotechnology, Santa Cruz, CA, USA), plasminogen activator inhibitor-1 (PAI-1), cytochrome $c$, Bax, Nrf2 (1:1000 dilution; Abcam, Cambridge, UK), caspase 9, caspase 3 (1:1000 dilution; Cell Signaling Technology, Beverly, MA, USA). The blots were washed three times in TBST for $15 \mathrm{~min}$ and then immersed in an appropriate secondary antibody at room temperature for $1 \mathrm{~h}$. The membranes were washed three times for $45 \mathrm{~min}$ in TBST. The immunoblotted proteins were visualized using an enhanced chemiluminescence method. Protein bands were imaged using a Bio-Spectrum Gel Imaging System (Bio-Rad, Hercules, CA, USA). Bands were normalized with actin as an internal control.

\section{Statistical Analysis}

Data were expressed as mean \pm s.d. from at least three independent experiments. All data were processed by the Graphpad Prism 5.0 software (GraphPad Software, San Diego, CA, USA). Means from multiple groups were analyzed for statistical significance using a one-way analysis of variance and a post hoc comparison to identify significant differences between specific groups. Student's $t$-test was used to compare means from two groups. Kruskal-Wallis and Mann-Whitney tests were used to compare the lung fibrosis score. Results with $P<0.05$ were deemed significant. Data were analyzed using a statistical software package SPSS 20.0 (SPSS; Chicago, IL, USA).

\section{RESULTS}

\section{EE Reduced Cell Counts in BALF in $\mathrm{SiO}_{2}$-Induced Pulmonary Fibrosis in Mice}

Cell counts of total leukocytes, neutrophils, macrophages, and lymphocytes in BALF, the most sensitive markers of the pulmonary response, were analyzed to evaluate the effect of $\mathrm{EE}$ on the accumulation of inflammatory cells to the lung on days 7,14 , and 28 after $\mathrm{SiO}_{2}$ instillation. $\mathrm{SiO}_{2}$ treatment caused an increase in the number of total leukocytes (Figure 1a) as well as the absolute number of macrophages (Figure 1b), neutrophils (Figure 1c), and lymphocytes (Figure 1d) in BALF. In addition, neutrophils and macrophages in BALF were elevated to the peak in early phase, whereas lymphocytes in late phase. However, $\mathrm{SiO}_{2}$-induced enhancement in the number of inflammatory cells in BALF was reduced in mice receiving EE (Figure 1). On day 14, the augmentation of the number of macrophages in BALF caused by $\mathrm{SiO}_{2}$ was significantly reduced by the treatment of $\mathrm{EE}$ 
Table 1 Quantitative cell count of total leukocytes, macrophages, neutrophils, and lymphocytes in BALF

\begin{tabular}{|c|c|c|c|c|c|}
\hline Time & Group & Total cells $\left(* 10^{4} / \mathrm{ml}\right)$ & Macrophage $\left(* 10^{4} / \mathrm{ml}\right)$ & Neutrophil $\left({ }^{*} 10^{4} / \mathrm{ml}\right)$ & Lymphocyte $\left({ }^{*} 10^{4} / \mathrm{ml}\right)$ \\
\hline \multirow[t]{2}{*}{$7 d$} & Sham & $9.94 \pm 5.57$ & $7.34 \pm 4.14$ & $0.43 \pm 0.27$ & $2.17 \pm 1.16$ \\
\hline & EE & $29.25 \pm 5.91^{\mathrm{a}}$ & $22.79 \pm 4.15^{\mathrm{a}}$ & $1.90 \pm 0.29$ & $4.56 \pm 1.92$ \\
\hline $14 d$ & Sham & $7.63 \pm 3.71$ & $5.23 \pm 1.95$ & $0.56 \pm 0.37$ & $1.83 \pm 1.39$ \\
\hline \multirow[t]{3}{*}{$28 d$} & Sham & $4.00 \pm 0.35$ & $3.17 \pm 0.39$ & $0.16 \pm 0.04$ & $0.68 \pm 0.004$ \\
\hline & Silicosis & $19.58 \pm 3.62^{\mathrm{a}}$ & $15.32 \pm 3.32^{\mathrm{a}}$ & $0.55 \pm 0.08^{a}$ & $3.71 \pm 0.44^{\mathrm{a}}$ \\
\hline & EE & $10.50 \pm 0.66^{a, b}$ & $8.25 \pm 0.48^{\mathrm{a}}$ & $0.33 \pm 0.07^{\mathrm{a}, \mathrm{b}}$ & $1.92 \pm 0.44^{\mathrm{a}, \mathrm{b}}$ \\
\hline
\end{tabular}

${ }^{\mathrm{a}} P<0.05$ compared with sham group (one-way ANOVA followed by Bonferroni multiple comparisons test).

${ }^{\mathrm{b}} \mathrm{P}<0.05$ compared with silicosis group (one-way ANOVA followed by Bonferroni multiple comparisons test).

$(P<0.05)$. On day 28, the number of total leukocytes, lymphocytes, and neutrophils in BALF was significantly less in the EE group than those in the silicosis group $(P<0.05$; Table 1).

\section{EE Attenuates $\mathrm{SiO}_{2}$-Induced Pulmonary Fibrosis In Vivo} Histopathological examination revealed that $\mathrm{SiO}_{2}$-injured lungs suffered loss of normal alveolar structure, alveolar wall thickening, massive infiltration of inflammatory cells, and were characterized by the formation of silicotic nodules mainly around the bronchial tree and vascular beds. Fibrosis began from day 14 in the model group, and progressively developed until day 28, when it reached a peak (Figure 2). However, the destructive effect of $\mathrm{SiO}_{2}$ in the $\mathrm{EE}$ group was relieved compared with that in the silicosis group at all time points (Figure 2). The mice in the sham group showed no histological changes (Figure 2). To quantify the degree of lung fibrosis, pathological sections on day 28 after $\mathrm{SiO}_{2}$ instillation were graded in terms of severity and distribution of the lesions. As shown in Table 2, mice of the silicosis group showed a significant increase $(P<0.05)$ in the severity and the distribution grades of the lesions in the lung as compared with the mice of the sham group. In contrast, significantly reduced $(P<0.05)$ severity and distribution grades of the lesions were detected in the EE group compared with the silicosis group (Table 2).

\section{EE Improves Lung Structure and Function In Vivo}

To visualize and evaluate the lung structure and function by imaging, micro-CT was utilized. Figure $3 \mathrm{a}$ is tomogram of lung tissue. And high density (offwhite) region within the lung represents the fibrotic area in that section. As was shown by three-dimensional (3D) reconstruction of micro-CT scans (Figure 3b), EE-treated animals retained a larger volume of functional lung tissue after $\mathrm{SiO}_{2}$-induced injury. Reconstructed 3D images allow visualization of the topographical distribution of fibrosis and indicate EE improves the structure and function of lung in fibrotic mice. In addition to the qualitative imaging data, calculated $3 \mathrm{D}$ parameters of the in vivo micro-CT images resulted in a quantitative volume output, expressed as total voxel number. The voxel number of aerated lung volume of the silicosis group calculated by software was significantly less than that of the sham group $(P=0.030$, Table 3$)$; Although the EE group had a larger voxel number than the model group, it was not statistically significant $(P=0.231$, Table 3$)$.

\section{EE Attenuates $\mathrm{SiO}_{2}$-Induced Cytotoxicity in $\mathrm{HBE}$ and A549 Cells}

To investigate the mechanism underlying the protective effects of $\mathrm{EE}$ against pulmonary fibrosis induced by $\mathrm{SiO}_{2}$ in mice, we firstly explore the potential role of $\mathrm{EE}$ on $\mathrm{SiO}_{2}$-induced cytotoxicity in vitro. To select the optimal dose and time of $\mathrm{SiO}_{2}$ and EE treatment, we incubated HBE and A549 cells at different hours with treatment of increasing concentrations of $\mathrm{SiO}_{2}$. The findings showed that $\mathrm{SiO}_{2}$ significantly inhibited the viability of $\mathrm{HBE}$ (Figure $4 \mathrm{a}$ and b) and A549 (Figure 4d and e) cells with dose- and time-dependent manners. $\mathrm{SiO}_{2}$ at the concentration of $200 \mu \mathrm{g} / \mathrm{ml}$ for $24 \mathrm{~h}$ significantly decreased the cell viability of $\mathrm{HBE}$ and $\mathrm{A} 549$ to about $50 \%$ and these conditions were therefore selected for the rest of the experiments (Figure $4 \mathrm{a}, \mathrm{b}, \mathrm{d}$, and e).

Then, HBE and A549 cells were co-treated with $200 \mu \mathrm{g} / \mathrm{ml}$ $\mathrm{SiO}_{2}$ and various doses of EE or NAC for $24 \mathrm{~h}$ to examine the protective effect of $\mathrm{EE}$ on $\mathrm{SiO}_{2}$-induced cytotoxicity. NAC, a precursor of the synthesis of reduced GSH, was used as the positive control in our in vitro experiments, since it has been shown to alleviate $\mathrm{SiO}_{2}$-induced oxidative stress and mitochondrial apoptosis signaling in rats' lung fibrosis. ${ }^{24}$ Notably, EE with concentrations of 1 and $2 \mathrm{U} / \mu \mathrm{l}$ and NAC with concentrations of 0.1 and $1 \mathrm{mM}$ obviously enhanced the cell 

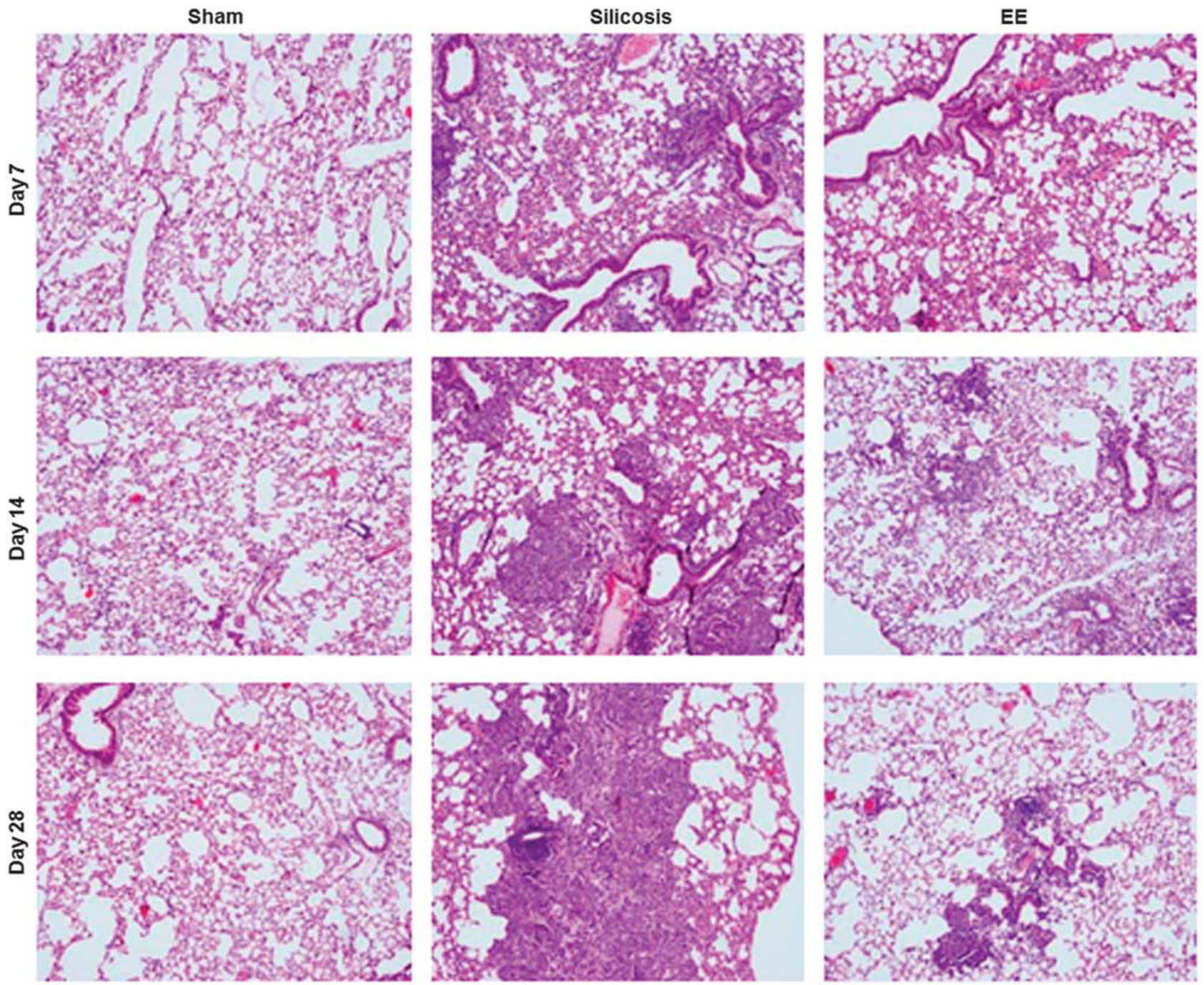

Figure $2 \mathrm{EE}$ attenuates $\mathrm{SiO}_{2}$-induced pulmonary fibrosis in vivo. Animals and treatments are as described under Materials and Methods. EE protected against histopathological changes induced by $\mathrm{SiO}_{2}$ as assessed by H\&E staining of sections of lung tissues on days 7,14 , and 28 after instillation. Representative photomicrographs are shown (magnification, 100X).

Table 2 Alterations in lesion severity and distribution in lungs in response to treatment with EE (day 28)

\begin{tabular}{|c|c|c|c|c|c|c|c|c|c|c|c|c|c|}
\hline \multirow[t]{2}{*}{ Groups } & \multicolumn{5}{|c|}{$\begin{array}{l}\text { Lesion severity } \\
\text { grade }\end{array}$} & \multirow[t]{2}{*}{$\begin{array}{l}\text { Average } \\
\text { severity } \\
\text { grade }\end{array}$} & \multicolumn{6}{|c|}{$\begin{array}{l}\text { Lesion } \\
\text { distribution } \\
\text { grade }\end{array}$} & \multirow[t]{2}{*}{$\begin{array}{l}\text { Average } \\
\text { distribution } \\
\text { grade }\end{array}$} \\
\hline & $\begin{array}{ll}0 & 1\end{array}$ & 2 & 3 & 4 & 5 & & 0 & 1 & 2 & 34 & 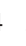 & & \\
\hline Sham & 42 & & & & & $0.33 \pm 0.52$ & 4 & 2 & & & & & $0.33 \pm 0.52$ \\
\hline Silicosis & & 2 & 2 & 1 & 1 & $3.17 \pm 1.17^{\mathrm{a}}$ & & & 2 & 21 & & & $3.17 \pm 1.17^{a}$ \\
\hline EE & 4 & 2 & & & & $1.33 \pm 0.52^{b}$ & & 4 & 2 & & & & $1.33 \pm 0.52^{b}$ \\
\hline
\end{tabular}

${ }^{a} P<0.05$ compared with sham group (Kruskal-Wallis test followed by the Mann-Whitney U-test).

${ }^{\mathrm{b}} P<0.05$ compared with silicosis group (Kruskal-Wallis test followed by the Mann-Whitney U-test). viability of $\mathrm{HBE}$ and $\mathrm{A} 549$, so these conditions were selected for further studies (Figure $4 \mathrm{c}$ and $\mathrm{f}$ ). The effect of EE alone on cell viability was also investigated in HBE and A549 cells. The results are shown in Supplementary Figure 2 where EE $(1-4 \mathrm{U} / \mu \mathrm{l})$ has no obvious growth or toxic effects in HBE and A549 cells. These results indicate that the viability of $\mathrm{SiO}_{2}$-treated cells decreased significantly, and EE exerted a protective effect against $\mathrm{SiO}_{2}$-induced cytotoxicity in $\mathrm{HBE}$ and A549 cells, which may be correlated with its antioxidative activity.

\section{EE Prevents $\mathrm{SiO}_{2}$-Induced Apoptosis of HBE and A549 Cells}

To understand the molecular mechanism underlying the improvement of growth suppression of HBE and A549 cells by $\mathrm{EE}$, we examined the impact of $\mathrm{EE}$ on $\mathrm{SiO}_{2}$-induced 

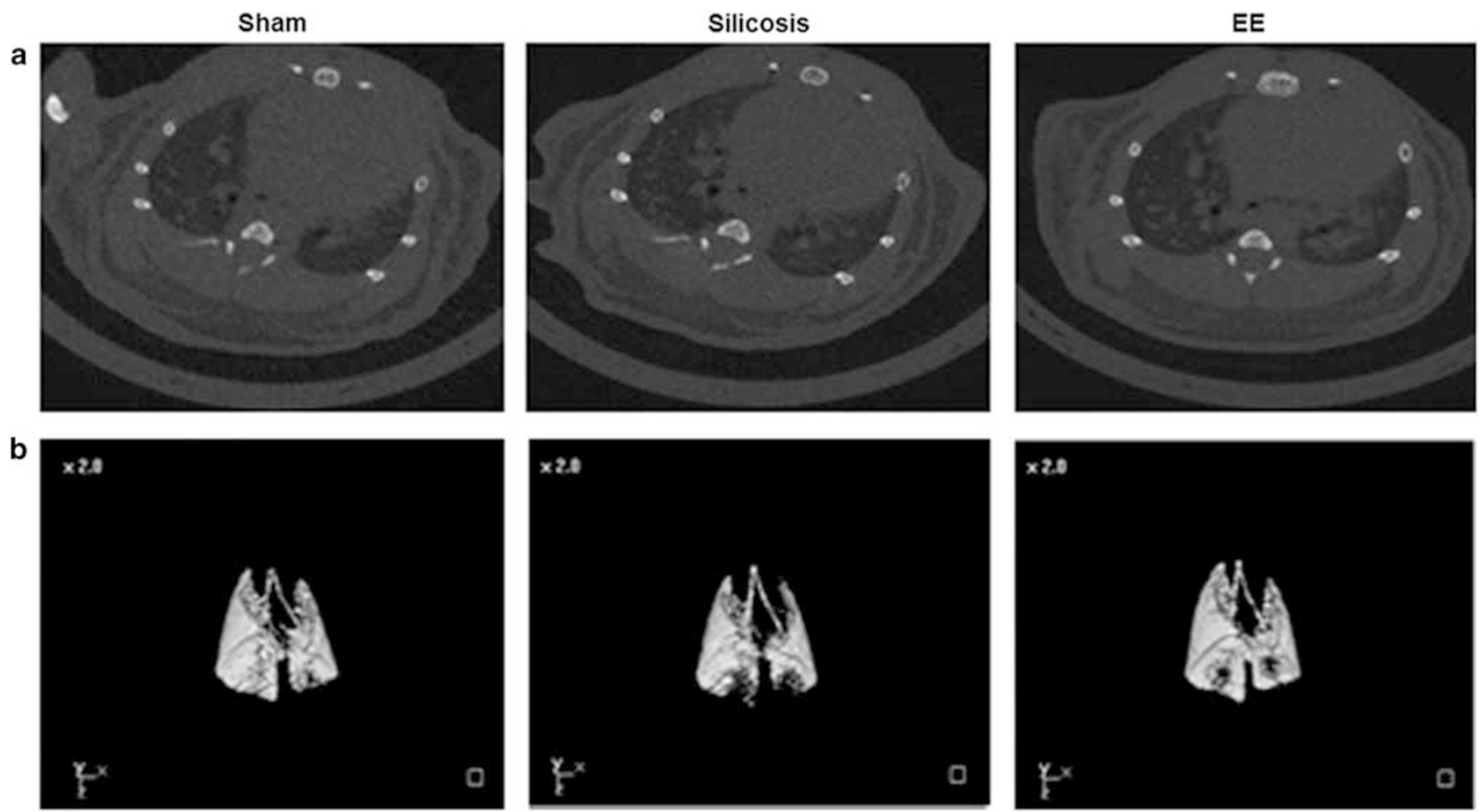

Figure $3 \mathrm{EE}$ improves lung structure and function in vivo. Animals and treatments are as described under Materials and Methods. (a) Representative tomogram in sham, silicosis, and EE groups on day 28 after induction of fibrosis using automated micro-CT. (b) Representative 3D micro-CT imaging on day 28.

Table 3 Number of voxels of aerated lung volume (day 28)

\begin{tabular}{lcc}
\hline Group & Mean \pm s.e. & $P$-value \\
\hline Sham & $10075200 \pm 888000$ & Reference \\
Silicosis & $8375100 \pm 119157$ & 0.030 \\
EE & $9220100 \pm 560254$ & 0.231 \\
\hline
\end{tabular}

apoptosis of HBE and A549 cells. The morphological changes of apoptotic cells, which featured typical characteristics, including contracted nucleus and condensed chromatin fragments, were identified by Hoechst 33258 staining, as illustrated in Figure 5a. Following treatment with $200 \mu \mathrm{g} / \mathrm{ml}$ $\mathrm{SiO}_{2}$ for $24 \mathrm{~h}$, the number of apoptotic cells increased significantly compared with the control group in $\mathrm{HBE}$ and A549 cells. However, co-treatment with EE or NAC obviously decreased the number of apoptotic cells in HBE and A549 cells (Figure 5b and c).

\section{EE Improves the Condition of Mitochondria Induced by $\mathrm{SiO}_{2}$ in $\mathrm{HBE}$ and $\mathrm{A} 549$ Cells}

Mitochondria are the power stations of cells and the preferential target of many xenobiotics. Dissipation of mitochondrial integrity, indicated as a decline in MMP, is one of the early events associated with the initiation and activation of some apoptotic signaling cascades, such as the release of cytochrome $c$ from mitochondria into the cytoplasm. To assess whether EE affects the function of mitochondria, the changes of MMP were analyzed by employing mitochondria fluorescence dye, JC-1, which stains mitochondria in a membrane potential-dependent manner. As shown in Figure 6a and b, HBE and A549 cells exposed to $200 \mu \mathrm{g} / \mathrm{ml} \mathrm{SiO}_{2}$ for $24 \mathrm{~h}$ resulted in a decrease in aggregate and an increase in monomer forms of JC-1 compared with the control group, which represented the MMP loss. However, co-treatment with EE or NAC both significantly prevented the disruption of MMP (Figure $6 \mathrm{c}$ and $\mathrm{d}$ ).

To determine whether the dysfunction of mitochondrial energy generation occurred in $\mathrm{SiO}_{2}$-treated cells, we tested the changes of intracellular ATP content in HBE and A549 cells. As shown in Figure 6e and f, when cells were treated with $200 \mu \mathrm{g} / \mathrm{ml} \mathrm{SiO}_{2}$ for $24 \mathrm{~h}$, ATP concentration markedly decreased compared with cells from the control group. However, in the presence of EE, ATP concentrations were significantly increased and NAC also inhibited the decrease of ATP levels induced by $\mathrm{SiO}_{2}$. Our data demonstrates that EE avoids the mitochondrial dysfunction induced by $\mathrm{SiO}_{2}$ in HBE and A549 cells.

\section{EE Alleviates $\mathrm{SiO}_{2}$-Induced Apoptosis Through the Mitochondrial Pathway In Vivo and In Vitro}

To further confirm $\mathrm{EE}$ could reverse $\mathrm{SiO}_{2}$-induced disruption of MMP through the inhibition of the release of 
a

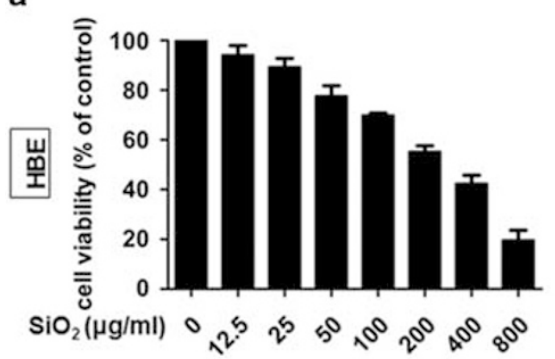

d

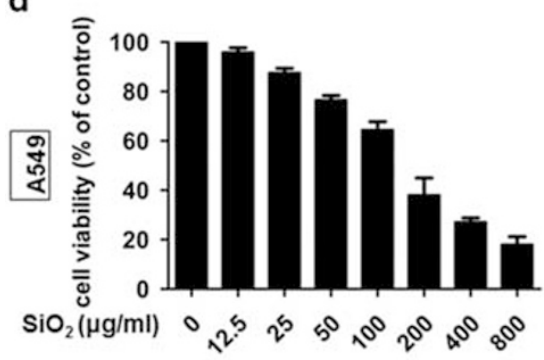

b
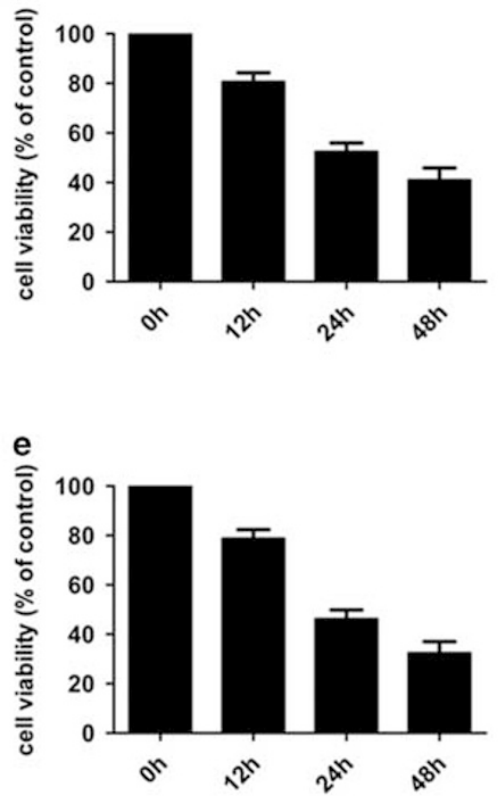

c

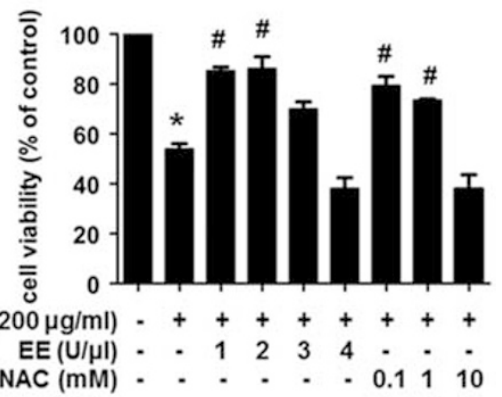

f

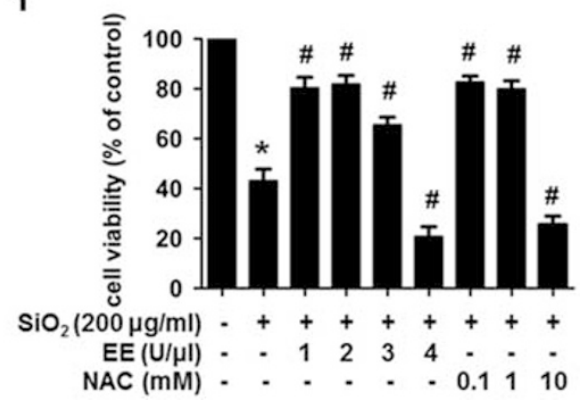

Figure 4 EE attenuates $\mathrm{SiO}_{2}$-induced cytotoxicity in $\mathrm{HBE}$ and $\mathrm{A} 549$ cells. (a, $\left.\mathbf{b}, \mathbf{d}, \mathbf{e}\right) \mathrm{SiO}_{2}$ suppressed cell proliferation in a concentration- and timedependent manner in HBE and A549 cells. HBE (a) and A549 (d) cells were cultured for $24 \mathrm{~h}$ in different concentrations of $\mathrm{SiO}_{2}(0-800 \mu \mathrm{g} / \mathrm{ml})$. $\mathrm{HBE}(\mathbf{b})$ and A549 (e) cells were incubated with $200 \mu \mathrm{g} / \mathrm{ml} \mathrm{SiO}_{2}$ for 12, 24, and $48 \mathrm{~h}$. (c, f) EE improved cell viability in HBE and A549 cells. HBE (c) and A549 (f)

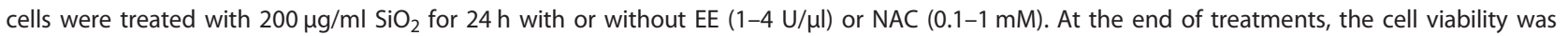
analyzed by CCK8 assay. Percentage of cell viability is relative to the untreated vehicle cells. Quantitative results are presented as mean \pm SD from three independent experiments performed in triplicate. ${ }^{*} P<0.05$ compared with the control group; ${ }^{\#} P<0.05$ compared with the $\mathrm{SiO}_{2}$ group.

cytochrome $c$ from the mitochondria into the cytoplasm, we examined the distribution and subcellular localization of cytochrome $c$ in HBE and A549 cells using immunofluorescence assay. As shown in Figure 7a, following treatment with $200 \mu \mathrm{g} / \mathrm{ml} \mathrm{SiO}_{2}$ for $24 \mathrm{~h}$, diffuse cytoplasmic staining was detected, in contrast to the obviously clear appearance in control cells, implying that cytochrome $c$ was released from the mitochondria to the cytosol. Moreover, co-treatment with EE or NAC both prevented the cytochrome $c$ release caused by $\mathrm{SiO}_{2}$ in $\mathrm{HBE}$ and $\mathrm{A} 549$ cells (Figure $7 \mathrm{a}$ ). In addition, the cytochrome $c$ levels markedly increased in the $\mathrm{SiO}_{2}$ treatment alone group. By contrast, the cytochrome $c$ levels markedly decreased after EE or NAC treatment in HBE and A549 cells (Figure $7 \mathrm{~b}$ and c). Furthermore, we observed whether EE was capable of accommodating the activation of caspase 9 and caspase 3, which are enzymes responsible for the execution of apoptosis. Western blot analysis indicated that, contrary to the $\mathrm{SiO}_{2}$-treated cells, the EE-treated cells had decreased expressions of cleaved-caspase 9 and cleaved-caspase 3 (Figure $7 \mathrm{~b}$ and $\mathrm{c}$ ).

Anti-apoptotic (Bcl-2) and pro-apoptotic (Bax) members of the Bcl-2 family have critical roles in maintaining mitochondrial integrity and mitochondria-initiated cytochrome $c$ release, leading to the activation of caspases in apoptosis. Our results showed that the protein level of Bax significantly increased and there was a prominent decrease in the protein expression of Bcl-2 after treatment with $200 \mu \mathrm{g} / \mathrm{ml}$ $\mathrm{SiO}_{2}$ in HBE and A549 cells. However, EE or NAC treatment inhibited $\mathrm{SiO}_{2}$-induced increase of $\mathrm{Bax}$ and decrease of $\mathrm{Bcl}-2$ (Figure $7 \mathrm{~b}$ and $\mathrm{c}$ ).

We also examined the Bax, Bcl-2, cytochrome $c$, cleavedcaspase 9, and cleaved-caspase 3 protein levels in the lung tissues from the sham, silicosis, and EE groups to reveal changes in the mitochondria-dependent apoptotic pathway. The cytochrome $c$, cleaved-caspase 9 , and cleaved-caspase 3 protein levels were significantly higher in silicosis mice than in sham animals as early as day 7. EE treatment significantly reversed these changes on days 7, 14, and 28 (Figure 7d). Besides, EE treatment effectively inhibited the expression of pro-apoptotic Bax and normalized the level of anti-apoptotic $\mathrm{Bcl}-2$ in fibrotic mice (Figure $7 \mathrm{~d}$ ). These results indicate that $\mathrm{SiO}_{2}$ activates the mitochondrial apoptotic pathway, but EE prevents it.

\section{EE Inhibits $\mathrm{SiO}_{2}$-Induced Cytokines Production and EMT In Vivo and In Vitro}

The production of inflammatory and fibrotic cytokines from lung epithelial cells is a hallmark of the pulmonary responses to fibrogenic silicious dust. We analyzed the interventional effect of $\mathrm{EE}$ against $\mathrm{SiO}_{2}$-stimulated production of representative cytokines in vivo and in vitro, including TGF- $\beta 1$, IL- $1 \beta$, and PAI-1, whose expressions are commonly altered during 
a

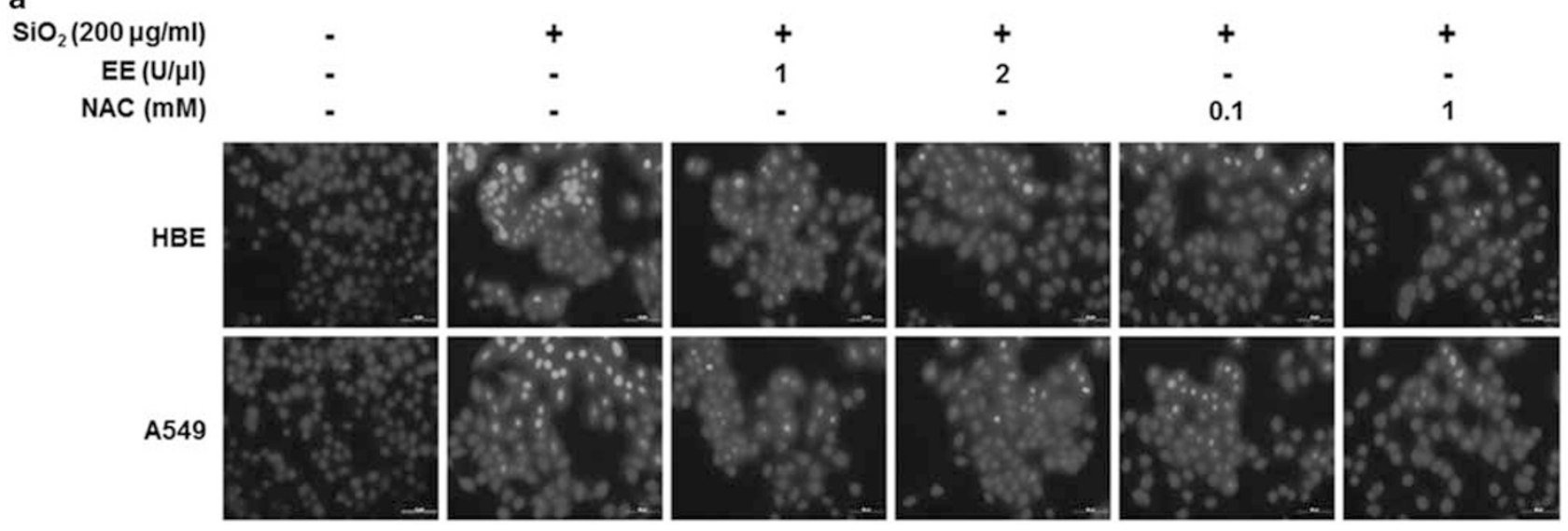

b

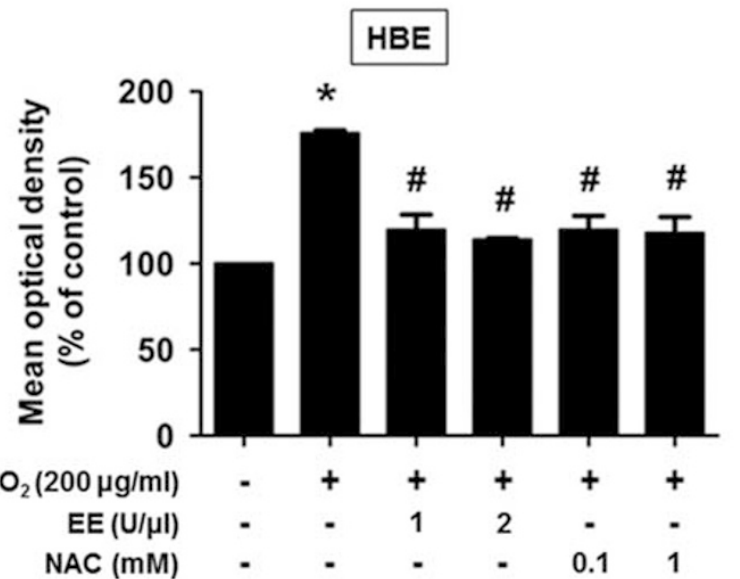

C

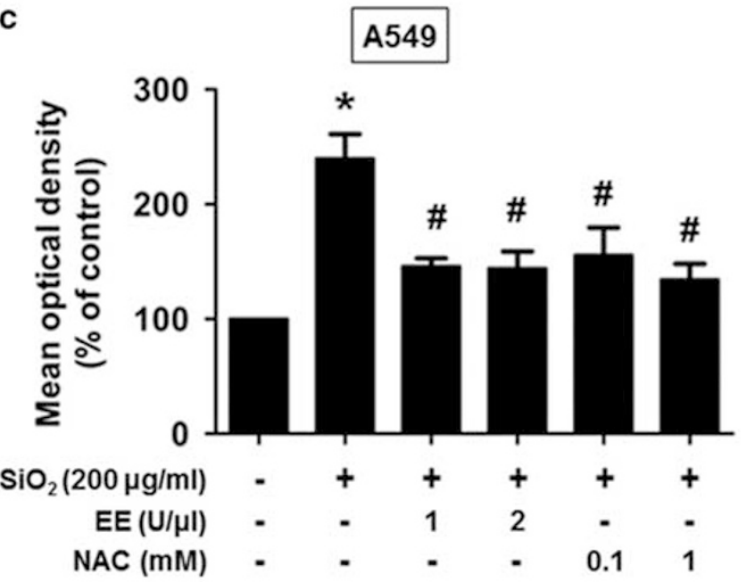

Figure 5 EE prevents apoptosis of lung epithelial cells in vitro. (a) Hoechst 33258 staining of lung epithelial cells. HBE and A549 cells treated with EE or NAC were incubated with $\mathrm{SiO}_{2}(200 \mu \mathrm{g} / \mathrm{ml})$ for $24 \mathrm{~h}$, and then subjected to Hoechst 33258 staining and observed under a fluorescence microscope. Representative images are shown (magnification, 400x). (b, c) Quantitative results for Hoechst 33258 staining presented as mean \pm SD of images' mean optical density from three independent experiments in HBE (b) and A549 (c) cells, respectively, using Image J software (http://imagej.nih.gov/ij/). ${ }^{*} P<0.05$ compared with the control group; ${ }^{\#} P<0.05$ compared with the $\mathrm{SiO}_{2}$ group.

inflammation and fibrosis. We found that the expression of TGF- $\beta 1$, IL- $1 \beta$, and PAI- 1 was significantly increased in the $\mathrm{SiO}_{2}$-treated $\mathrm{HBE}$ and $\mathrm{A} 549$ cells compared with control cells. On treatment with EE or NAC, TGF- $\beta 1$, IL- $1 \beta$, and PAI-1 levels were significantly reduced (Figure $8 \mathrm{a}$ and $\mathrm{b}$ ). In addition, the levels of TGF- $\beta 1$, IL- $1 \beta$, and PAI- 1 in silicosis model group were significantly increased compared with the sham group, and these changes were reversed by $\mathrm{EE}$ (Figure 8c).

Then, the effect of EE in preventing $\mathrm{SiO}_{2}$-stimulated EMT in epithelial cell and lung tissue of mice was examined. As shown in Figure 8a, treatment with $\mathrm{SiO}_{2}$ in HBE cells for $24 \mathrm{~h}$ led to a marked decrease in E-cadherin expression and an increase in $\alpha$-SMA expression. EE or NAC significantly prevented $\mathrm{SiO}_{2}$-stimulated changes of the E-cadherin and $\alpha$ SMA expression in HBE cells. Similar results were also obtained in A549 cells (Figure 8b). Consistent with the results of in vitro tests, animal study revealed the elevated $\alpha$-SMA expression and reduced E-cadherin expression in the silicosis group compared with the sham group. However, EE treatment significantly suppressed the level of $\alpha$-SMA and restored the level of E-cadherin (Figure 8c). These results suggest that EE prevents EMT both in vivo and in vitro.

\section{EE Contributes to the Protection Against $\mathrm{SiO}_{2}$-Induced Oxidative Stress In Vivo and In Vitro}

ROS generation is an important indicator of oxidative stress. To determine the capability of EE scavenging free radicals, the DCFH-DA assay was used to detect the generation of intracellular ROS induced by $200 \mu \mathrm{g} / \mathrm{ml} \mathrm{SiO}_{2}$ for $24 \mathrm{~h}$. The fluorescence images showed that green fluorescence intensity markedly increased when HBE and A549 cells were incubated with $\mathrm{SiO}_{2}$. However, co-treatment with EE or NAC reduced the green fluorescence intensity (Figure $9 \mathrm{a}$ ). Figure $9 \mathrm{~b}$ and $\mathrm{c}$ shows the same result: exposure of HBE and A549 cells to $\mathrm{SiO}_{2}$ led to an increase of intracellular ROS level, which was approximately threefold relative to that of control cells. Co- 
a

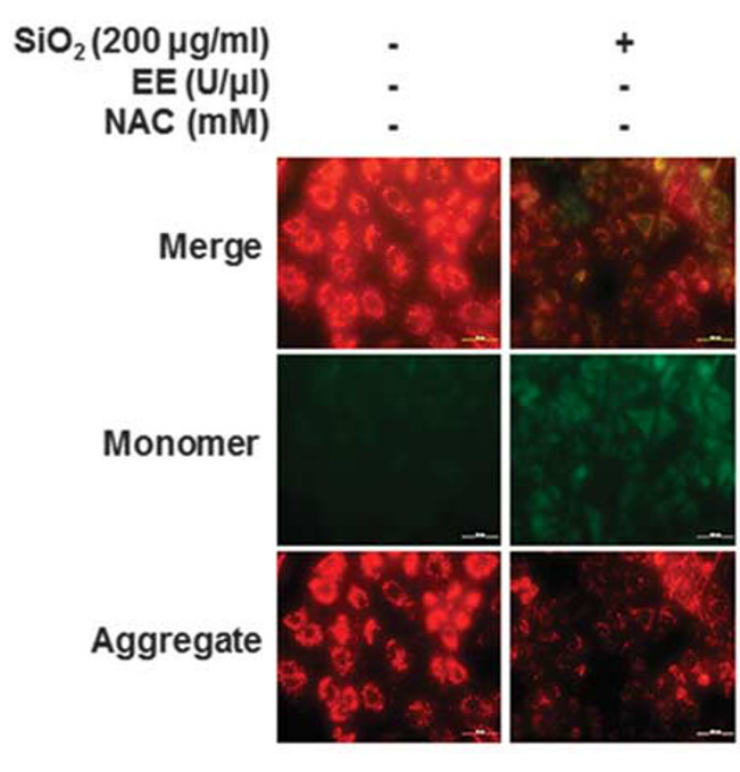

\section{HBE}
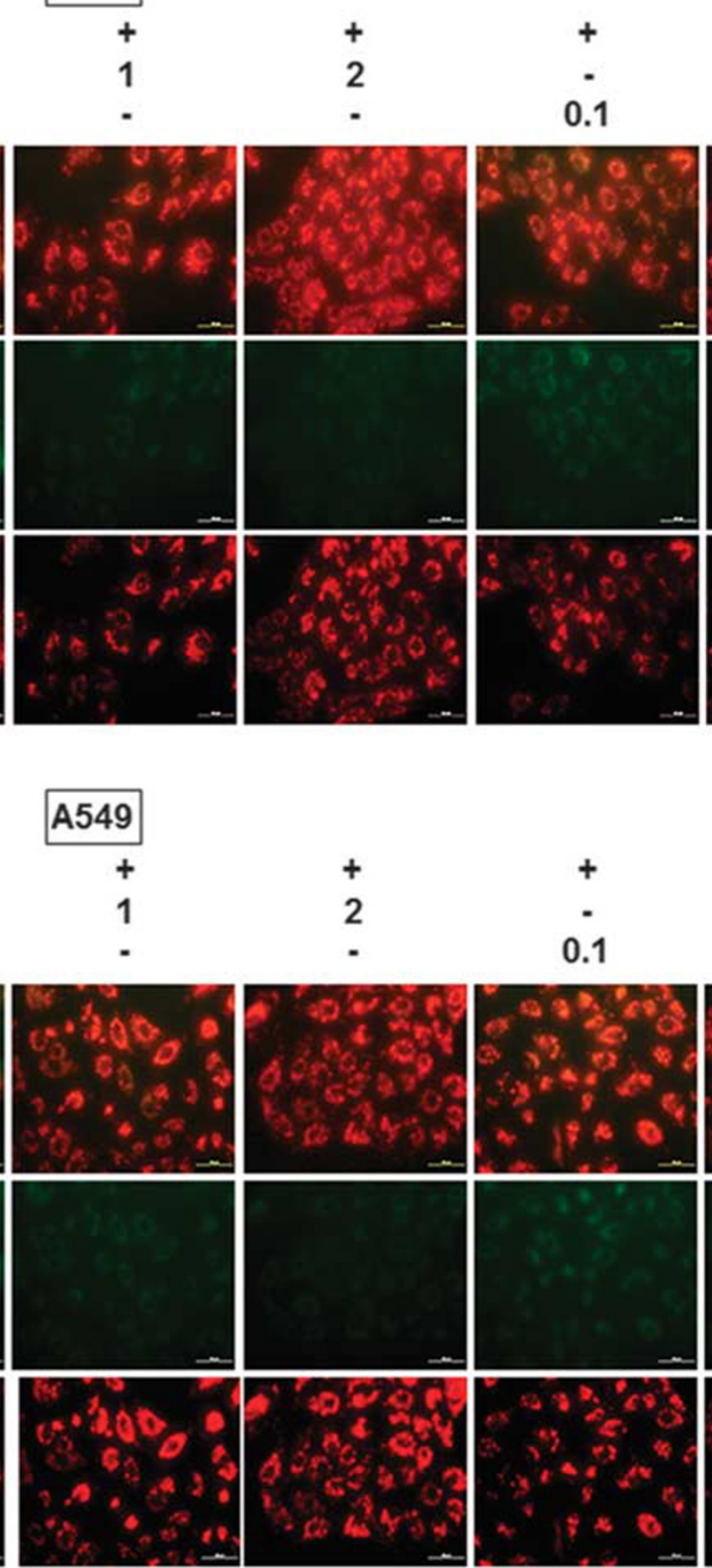

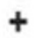

$-$

1
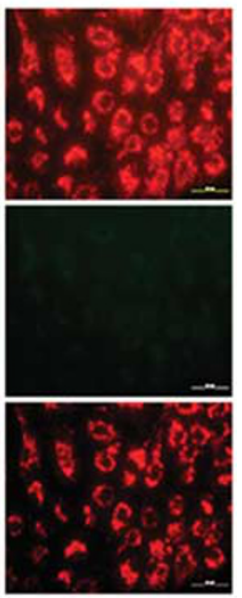

b

\section{Aggregate}
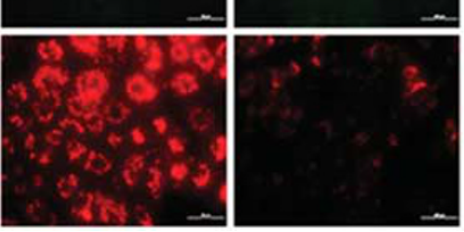

Figure 6 EE stabilizes the MMP and increases the ATP content in HBE and A549 cells. HBE and A549 cells were cultured with EE (1 or 2 U/ $\mu$ l) or NAC $(0.1$ or $1 \mathrm{mM})$ for $24 \mathrm{~h}$ under $\mathrm{SiO}_{2}(200 \mu \mathrm{g} / \mathrm{ml})$ stimulation. $(\mathbf{a}, \mathbf{b}) \mathrm{MMP}$ fluorescence images stained with $\mathrm{JC}-1$ visualized by a fluorescence microscope in HBE (a) and A549 (b) cells. Red fluorescence presents the mitochondrial aggregate form of JC-1, indicating intact MMP. Green fluorescence presents the monomeric form of JC-1, indicating the dissipation of MMP. Representative images are shown (magnification, $400 \times$ ). (c, d) Quantitative results for MMP. Red or green fluorescence intensity is reflected by the images' mean optical density using image J software (http://imagej.nih.gov/ij/). The intensity ratio of red and green are presented as mean \pm SD of from three independent experiments in HBE (c) and A549 (d) cells, respectively. ${ }^{*} P<0.05$ compared with the control group; ${ }^{\#} P<0.05$ compared with the $\mathrm{SiO}_{2}$ group. (e, f) Cellular ATP concentrations in HBE (e) and A549 (f) cells measured using firefly luciferase. Quantitative results are presented as mean \pm SD from three independent experiments. ${ }^{*} P<0.05$ compared with the control group; ${ }^{\#} P<0.05$ compared with the $\mathrm{SiO}_{2}$ group.

treatment with EE or NAC significantly inhibited the elevated intracellular ROS level.

Major antioxidant defenses include antioxidant scavengers, such as total SOD (TSOD) and GSH. An increase in MDA, which is a lipid peroxidation end-product, indicates reduced antioxidant capacity. To further clarify the antioxidant ability of $\mathrm{EE}$ and the mechanisms through which $\mathrm{EE}$ exerts its antioxidant effect, we measured TSOD, GSH, and MDA levels in $\mathrm{HBE}$ and $\mathrm{A} 549$ cells as well as serum of mice. $\mathrm{SiO}_{2}$ stimulation significantly decreased TSOD activity and GSH/ 
C

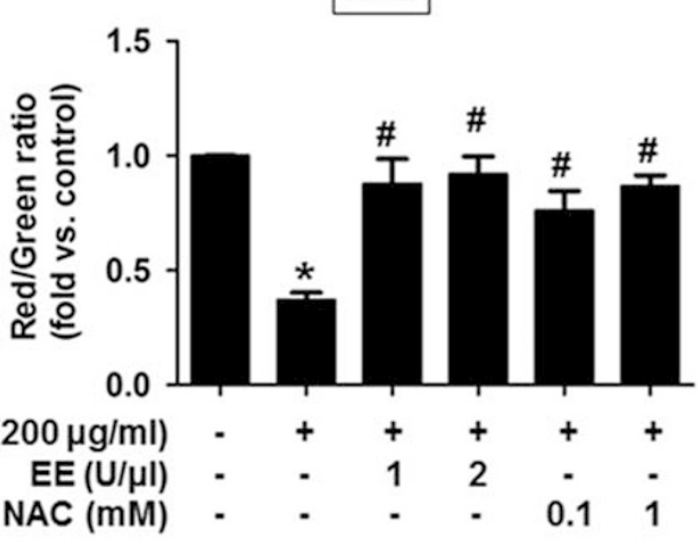

e

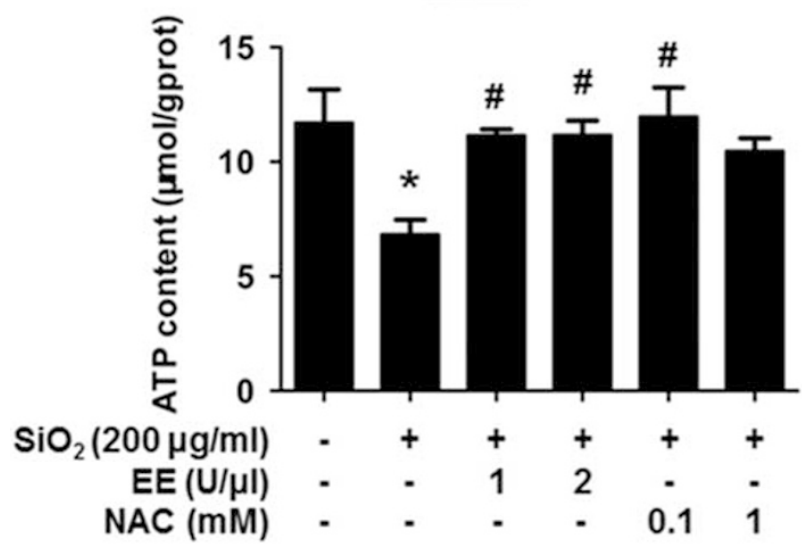

d

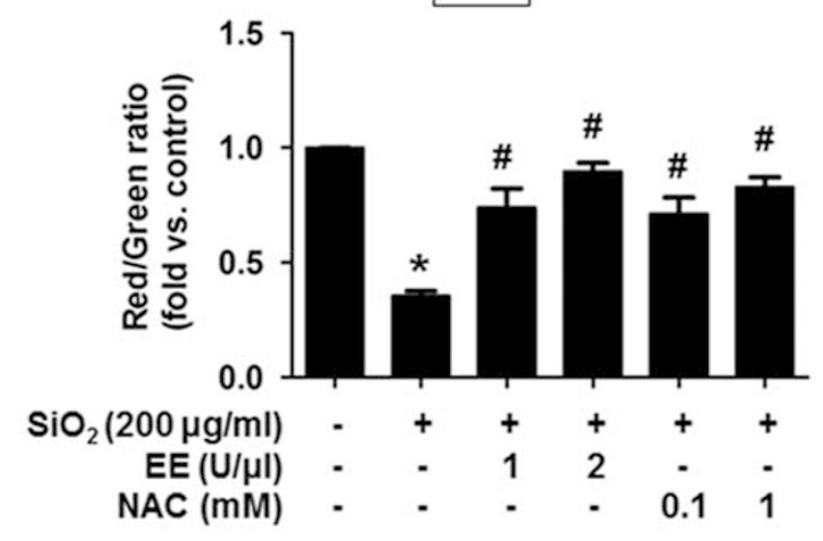

f

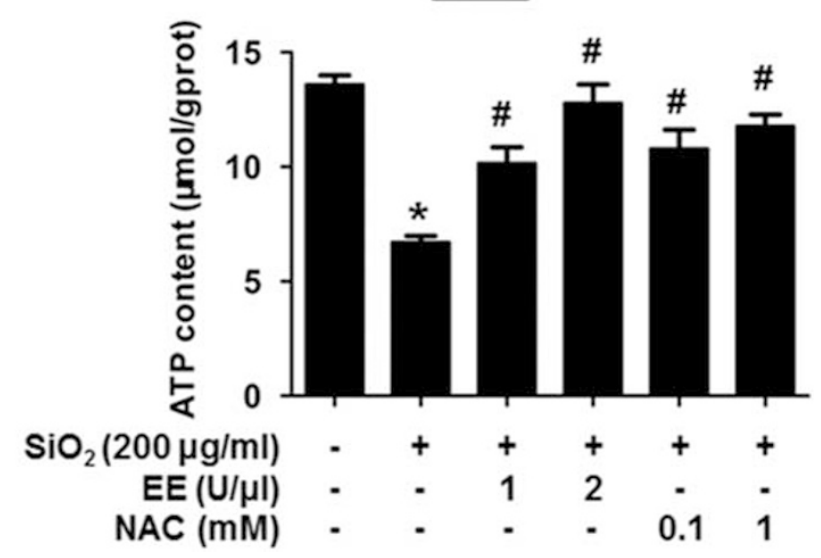

Figure 6 Continued.

GSSG and increased MDA content in HBE and A549 cells. Treatment of EE $(2 \mathrm{U} / \mu \mathrm{l})$ significantly enhanced TSOD activity and decreased MDA content in HBE and A549 cells (Figure 9d and e). Moreover, $1 \mathrm{mM}$ NAC markedly increased the TSOD activity and GSH/GSSG and decreased MDA content in $\mathrm{HBE}$ and $\mathrm{A} 549$ cells compared with the $\mathrm{SiO}_{2}$ treated cells (Figure $9 \mathrm{~d}$ and e). In serum of mice, $\mathrm{SiO}_{2}$ instillation induced notably decrease of TSOD and GSH/ GSSG and increase of MDA content. However, EE treatment markedly restored TSOD activity and reduced MDA content compared with those in the group of silicosis (Figure 9f).

\section{EE Activates Nrf2 to Induce Cytoprotective Genes In Vivo and In Vitro}

$\mathrm{Nrf} 2$ is a key transcriptional regulator for the protection of cells against oxidative stresses. The profound oxidative effect by $\mathrm{SiO}_{2}$ and its inhibition by EE in HBE and A549 cells raised the possibility that $\mathrm{Nrf} 2$ is involved in the actions of $\mathrm{SiO}_{2}$ and EE. As shown in Figure $10 \mathrm{a}, \mathrm{SiO}_{2}$ increased the protein level of Nrf2 in HBE and A549 cells, which were possibly related to the cell adaptive response. Co-treatment with $\mathrm{SiO}_{2}$ and $\mathrm{EE}$ further increased Nrf2 protein, suggesting a synergy between $\mathrm{SiO}_{2}$ and $\mathrm{EE}$ for Nrf2 activation. Immunofluorescence results showed that EE promoted the nuclear translocation of Nrf2 after $\mathrm{SiO}_{2}$ stimulation in $\mathrm{HBE}$ and A549 cells (Figure 10c and d). qRT-PCR was performed to analyze the induction of NQO-1 and HO-1, two representative target genes of Nrf2. Similar to Nrf2 response, HO-1 and NQO-1 mRNA were upregulated with $\mathrm{SiO}_{2}$ alone, and further increased with a combination of $\mathrm{SiO}_{2}$ plus $\mathrm{EE}$ in $\mathrm{HBE}$ and A549 cells (Figure $10 \mathrm{e}-\mathrm{h})$. In vivo study showed that $\mathrm{SiO}_{2}$ increased $\mathrm{Nrf} 2$ protein expression (Figure 10b) and the mRNA expression of its downstream antioxidant genes NQO-1 and HO-1 (Figure 10i and $j$ ) in the lung tissue of silicosis mice compared with the sham group. Moreover, EE treatment further promoted Nrf2 protein expression (Figure 10b) and its downstream antioxidant genes NQO-1 and $\mathrm{HO}-1$ at mRNA level (Figure $10 \mathrm{i}$ and $\mathrm{j}$ ). These data elucidate the possible involvement of $\mathrm{Nrf} 2$ activation behind the induction of antioxidant genes and protective effects of EE against $\mathrm{SiO}_{2}-$ induced oxidative stress. 
a $\mathrm{SiO}_{2}(200 \mu \mathrm{g} / \mathrm{m}$
$\mathrm{EE}(\mathrm{U} / \mu)$
$\mathrm{NAC}(\mathrm{mM})$
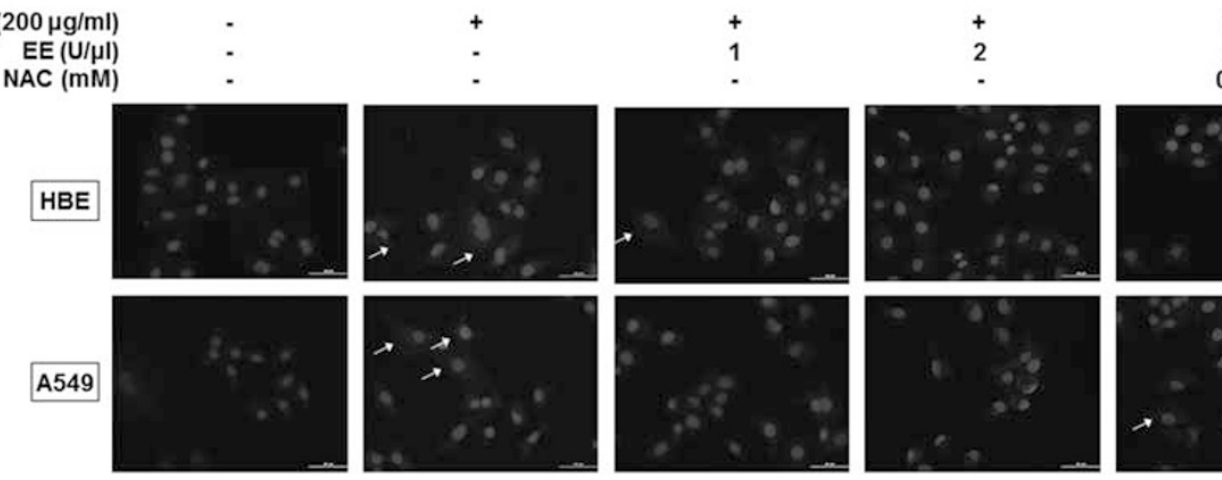

+
0.1
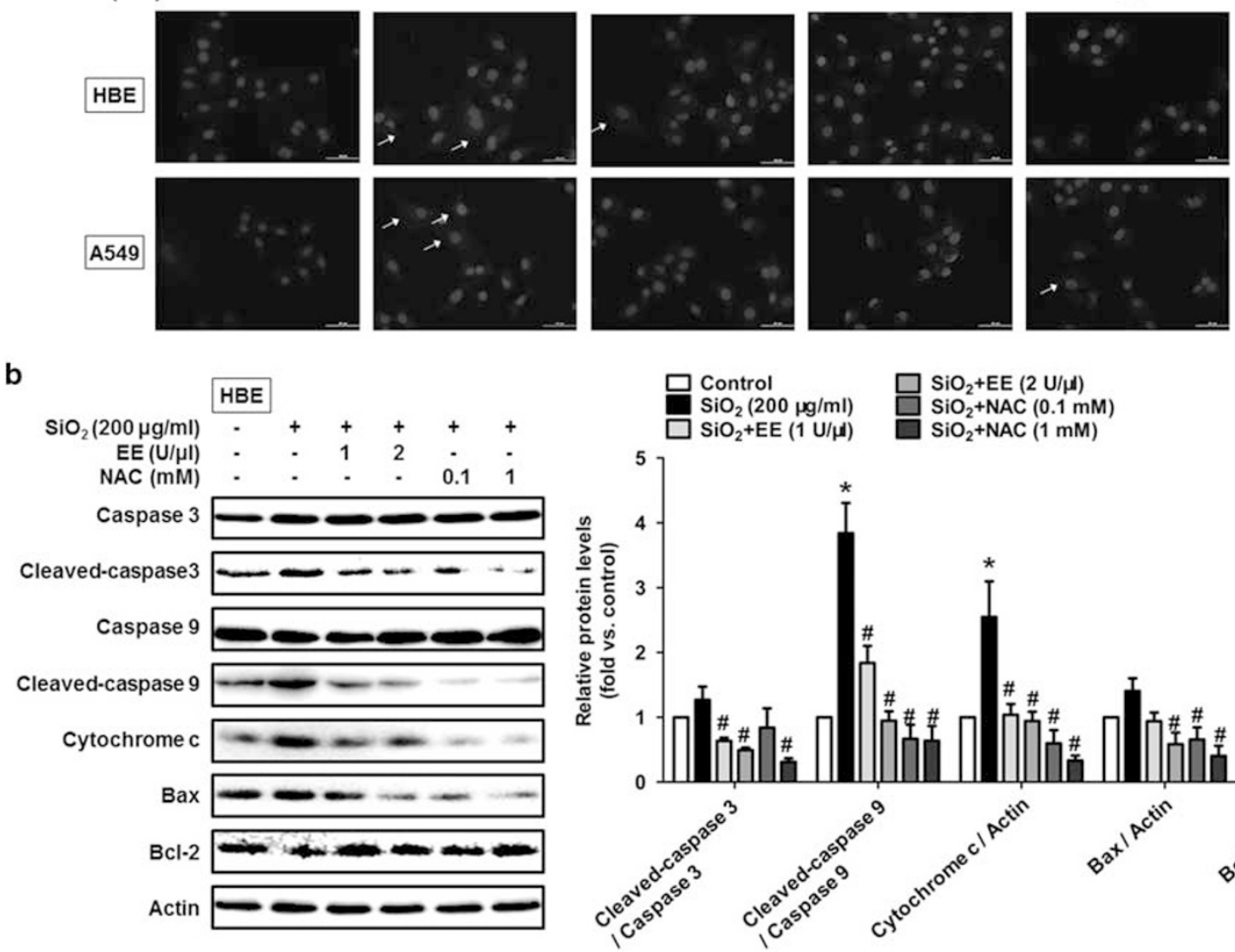

$\mathrm{O}_{2}+\mathrm{EE}(1 \mathrm{U} / \mathrm{\mu l})$

$\mathrm{SiO}_{2}+\mathrm{NAC}(1 \mathrm{mM})$

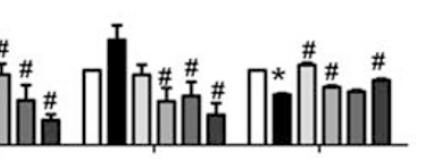

Figure $7 \mathrm{EE}$ prevents $\mathrm{SiO}_{2}$-induced mitochondria-mediated apoptosis in vivo and in vitro. Animals and treatments are as described under Materials and Methods. HBE and A549 cells were cultured with EE ( 1 or $2 \mathrm{U} / \mu \mathrm{l})$ or NAC $(0.1$ or $1 \mathrm{mM})$ for $24 \mathrm{~h}$ under $\mathrm{SiO}_{2}(200 \mu \mathrm{g} / \mathrm{ml})$ stimulation. (a) EE prevented the release of cytochrome $c$ from mitochondria to cytosol in HBE (up) and A549 (down) cells. The localization of cytochrome $c$ was detected by immunofluorescence staining. Cells were fixed and labeled for cytochrome $c$ (green) and nucleus (blue). Arrows indicate the cells with cytochrome $c$ release. Representative images are shown (magnification, 400X). (b) Western blot analysis of the expression levels of caspase 3/9, cleaved-caspase 3/9, cytochrome c, Bax, and Bcl-2 in HBE cells (left). Quantitative results are presented as mean \pm SD of the signal's optical density from three independent experiments (right). ${ }^{*} P<0.05$ compared with the control group; ${ }^{\#} P<0.05$ compared with the $\mathrm{SiO}_{2}$ group. (c) Western blot analysis of the expression levels of caspase 3/9, cleaved-caspase 3/9, cytochrome $c$, Bax, and Bcl-2 in A549 cells (left). Quantitative results are presented as mean \pm SD of the signal's optica density from three independent experiments (right). ${ }^{*} P<0.05$ compared with the control group; ${ }^{\#} P<0.05$ compared with the $\mathrm{SiO}_{2}$ group. (d) Western blot analysis of caspase 3/9, cleaved-caspase 3/9, cytochrome $c$, Bax, and Bcl-2 in lung tissues of mice from sham, silicosis, and EE groups on days 7, 14, and 28 after induction of fibrosis (left). Quantitative results are presented as mean \pm SD of the signal's optical density from three independent experiments (right). ${ }^{*} P<0.05$ compared with the sham group; ${ }^{\#} P<0.05$ compared with the silicosis group at the corresponding time point.

\section{Nrf2 Mediates the Protective Effects of EE Against $\mathrm{SiO}_{2}-$ Induced Cytotoxicity, Oxidative Stress, Mitochondrial Apoptosis, and EMT in HBE and A549 Cells}

To further confirm the protective effect of $\mathrm{EE}$ on $\mathrm{SiO}_{2}-$ induced cytotoxicity, oxidative stress, mitochondrial apoptosis, and EMT were mediated by Nrf2 activation, Nrf2 siRNA silencing technique was used. As shown in Figure 11a, Nrf2 siRNA effectively down-regulated the expression of Nrf2 in HBE and A549 cells, demonstrating the efficacy of this technique to silence $\mathrm{Nrf} 2 . \mathrm{SiO}_{2}$ at $200 \mu \mathrm{g} / \mathrm{ml}$ caused significant toxicity in wild type (WT) cells, and EE at $2 \mathrm{U} / \mu \mathrm{l}$ significantly reduced the toxicity in HBE cells (Figure 11b) in agreement with the data for A549 cells (Figure 11c). In Nrf2 gene silenced cells, $\mathrm{SiO}_{2}$ induced a higher level of toxicity than in WT cells and EE failed to rescue in HBE and A549 cells (Figure $11 \mathrm{~b}$ and c). The results indicate that Nrf2 is required for defense against $\mathrm{SiO}_{2}$ toxicity in normal cells and for protection effects by EE.

In WT cells, $200 \mu \mathrm{g} / \mathrm{ml} \mathrm{SiO}_{2}$ induced a dramatic increase of ROS production, but EE co-treatment blocked $\mathrm{SiO}_{2}$-induced ROS production in HBE and A549 cells (Figure 11d). In Nrf2 knock down (KO) HBE and A549 cells, the basal ROS production was increased (compare control $\mathrm{KO}$ with control WT); $\mathrm{SiO}_{2}$ induced a high level of ROS; and $\mathrm{EE}$ failed to block 
$\mathrm{SiO}_{2}$-induced ROS production. The data reveal that $\mathrm{Nrf2}$ is critically involved in the control of ROS production in HBE and A549 cells exposed to $\mathrm{SiO}_{2}$ and is required for the suppression of $\mathrm{SiO}_{2}$-induced oxidative stress by EE.

Nrf2 deletion alone did not obviously alter the MMP, but $200 \mu \mathrm{g} / \mathrm{ml} \mathrm{SiO}_{2}$ induced a significant decrease in aggregate and an increase in monomer forms of JC- 1 in both WT and Nrf2 KO cells of HBE and A549 (Figure 11e and f). Co-treatment with EE rescued the cells from $\mathrm{SiO}_{2}$-induced decline in MMP in WT but not Nrf2 KO cells of HBE and A549, indicating Nrf2 is required for EE protection against $\mathrm{SiO}_{2}$ toxicity to mitochondria.
C

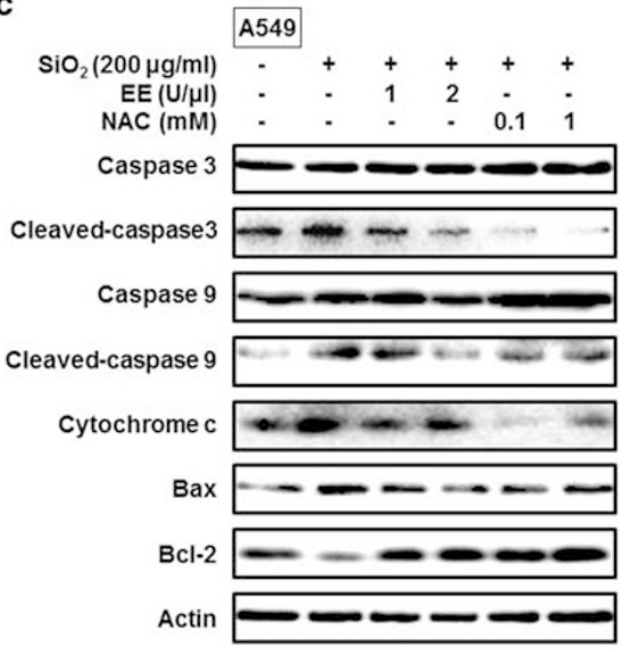

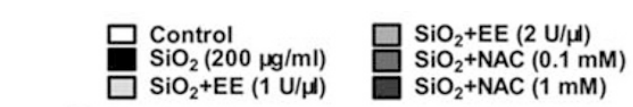
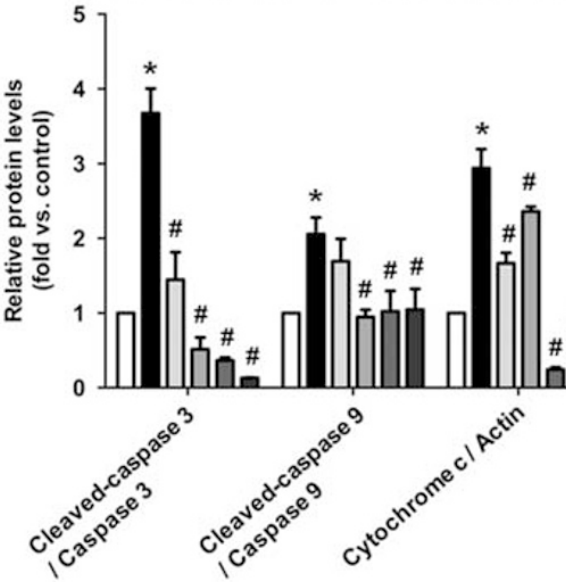

d
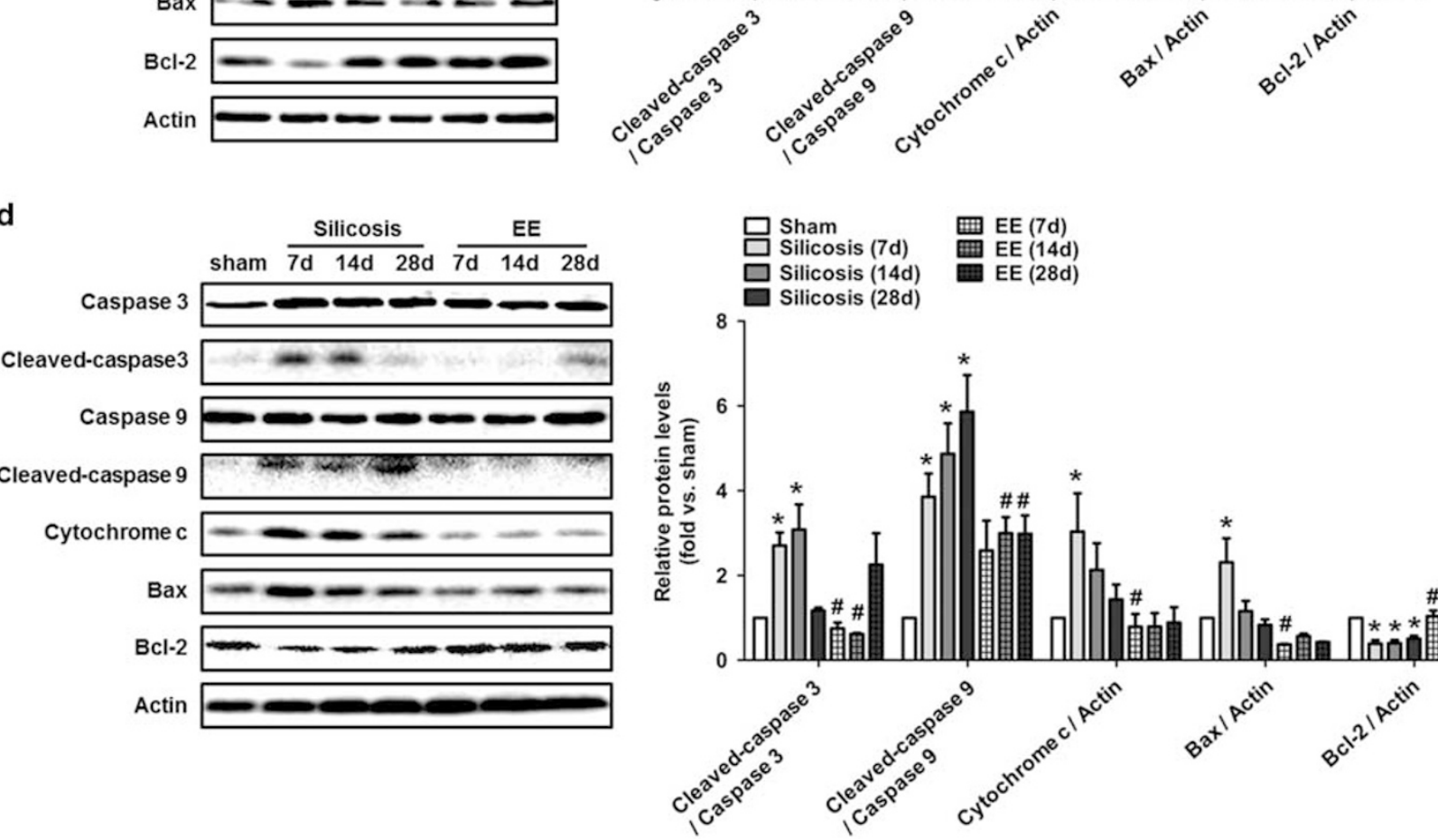

Figure 7 Continued.

Figure $8 \mathrm{EE}$ inhibits $\mathrm{SiO}_{2}$-induced cytokine production and $\mathrm{EMT}$ in vivo and in vitro. Animals and treatments are as described under Materials and Methods. HBE and A549 cells were cultured with EE (1 or $2 \mathrm{U} / \mu \mathrm{l})$ or NAC $(0.1$ or $1 \mathrm{mM})$ for $24 \mathrm{~h}$ under $\mathrm{SiO}_{2}(200 \mu \mathrm{g} / \mathrm{ml})$ stimulation. (a) Western blot analysis of the expression levels of TGF- $\beta 1$, PAI-1, IL-1 $\beta$, E-cadherin, and $a$-SMA in HBE cells (left). Quantitative results are presented as mean \pm SD of the signal's optical density from three independent experiments (right). ${ }^{*} P<0.05$ compared with the control group; ${ }^{\#} P<0.05$ compared with the $\mathrm{SiO}_{2}$ group. (b) Western blot analysis of the expression levels of TGF- $\beta 1$, PAI-1, IL-1 $\beta$, E-cadherin, and a-SMA in A549 cells (left). Quantitative results are presented as mean \pm SD of the signal's optical density from three independent experiments (right). ${ }^{*} P<0.05$ compared with the control group; ${ }^{\#} P<0.05$ compared with the $\mathrm{SiO}_{2}$ group. (c) Western blot analysis of TGF- $\beta 1, \mathrm{PAl}-1, \mathrm{IL}-1 \beta, \mathrm{E}$-cadherin, and a-SMA in lung tissues of mice from sham, silicosis, and EE groups on days 7,14 , and 28 after induction of fibrosis (left). Quantitative results are presented as mean \pm SD of the signal's optical density from three independent experiments (right). ${ }^{*} P<0.05$ compared with the sham group; ${ }^{\#} P<0.05$ compared with the silicosis group at the corresponding time point. 

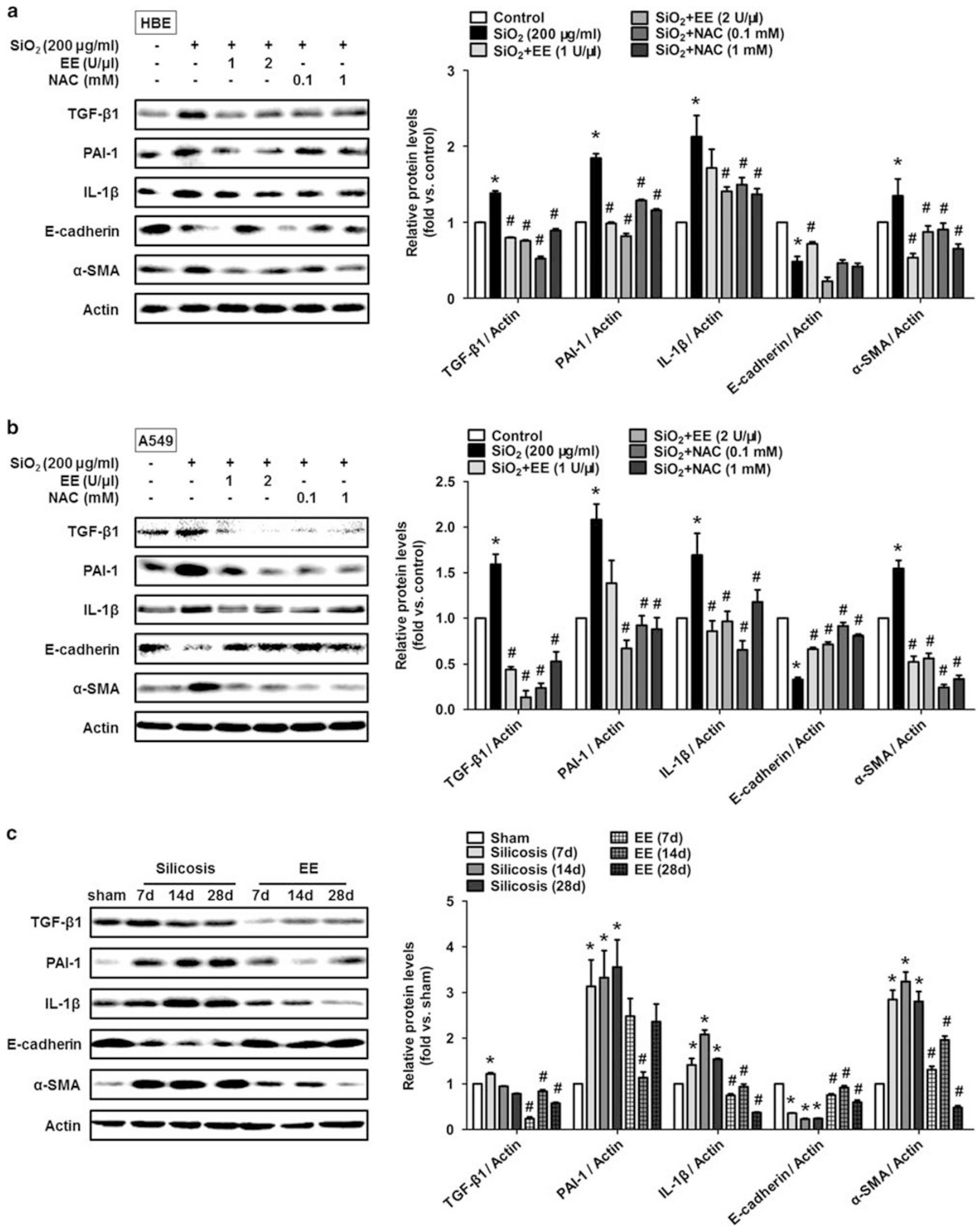


$$
\text { a }
$$

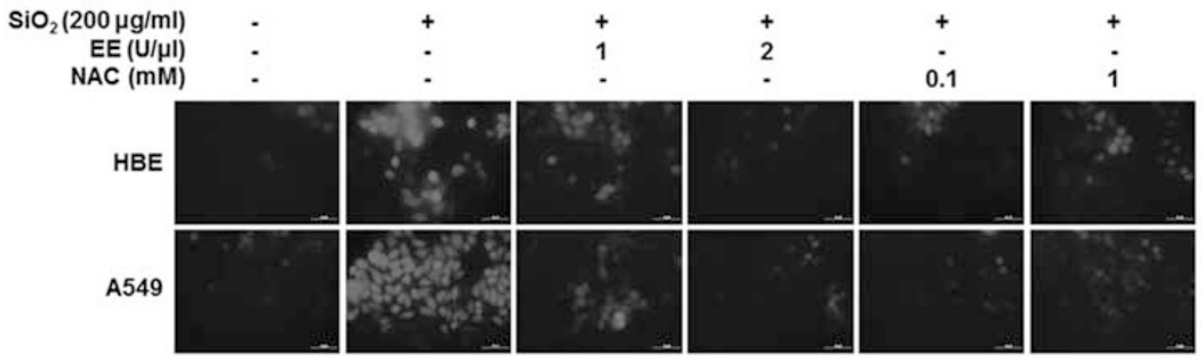

b

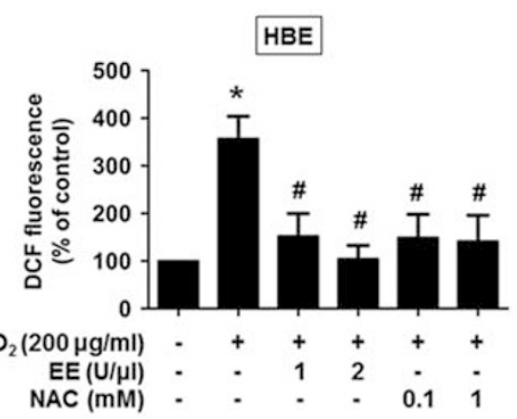

d

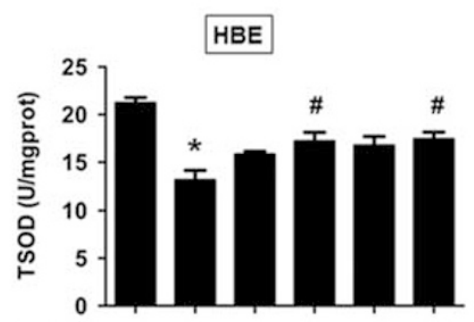

$\mathrm{SiO}_{2}(200 \mu \mathrm{g} / \mathrm{ml}) \cdot+++++$

$\mathrm{EE}(\mathrm{U} / \mu \mathrm{I}) \quad-\quad \cdot \quad \begin{array}{llll} & 1 & 2 & -\end{array}$

NAC (mM)

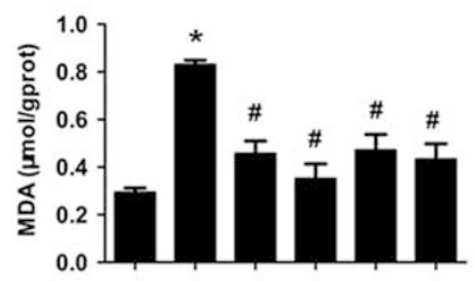

$\mathrm{SiO}_{2}(200 \mu \mathrm{g} / \mathrm{ml}) \cdot++\quad+\quad+\quad+$

$\begin{array}{llllll}E E(U / \mu l) & - & - & 1 & 2 & -\end{array}$

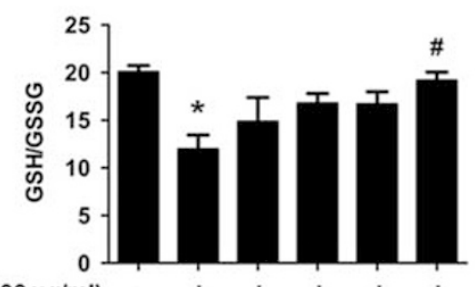

$\mathrm{SiO}_{2}(200 \mu \mathrm{g} / \mathrm{ml}) \cdot++++$

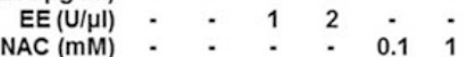

c
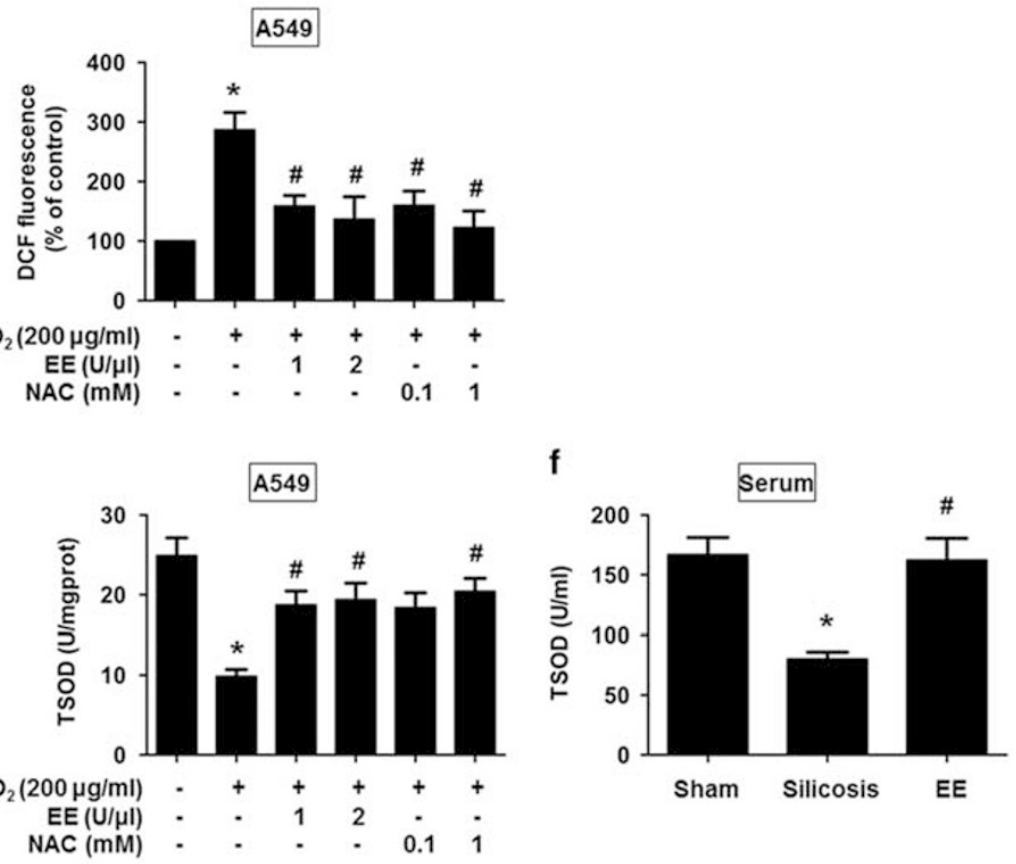

$\begin{array}{rcccccc}\mathrm{SiO}_{2}(200 \mu \mathrm{g} / \mathrm{ml}) & - & + & + & + & + & + \\ \mathrm{EE}(\mathrm{U} / \mu \mathrm{l}) & - & - & 1 & 2 & - & - \\ \mathrm{NAC}(\mathrm{mM}) & - & - & - & - & 0.1 & 1\end{array}$
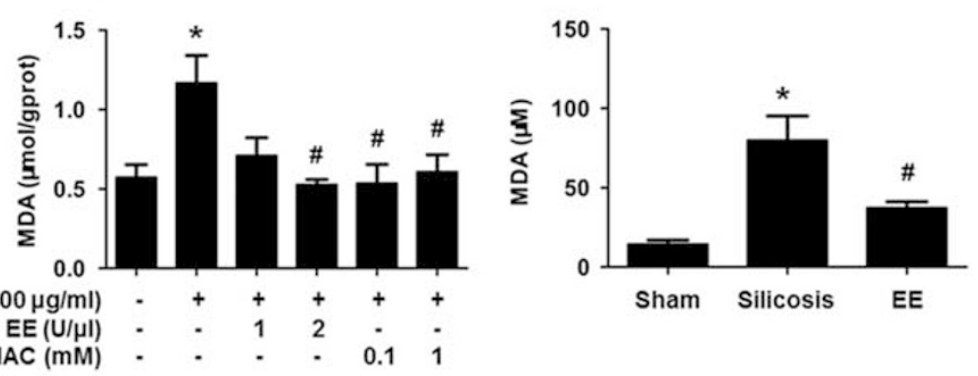

$\begin{array}{rcccccc}\mathrm{SiO}_{2}(200 \mu \mathrm{g} / \mathrm{ml}) & - & + & + & + & + & + \\ \mathrm{EE}(\mathrm{U} / \mu \mathrm{l}) & - & - & 1 & 2 & - & - \\ \mathrm{NAC}(\mathrm{mM}) & \cdot & - & - & - & 0.1 & 1\end{array}$
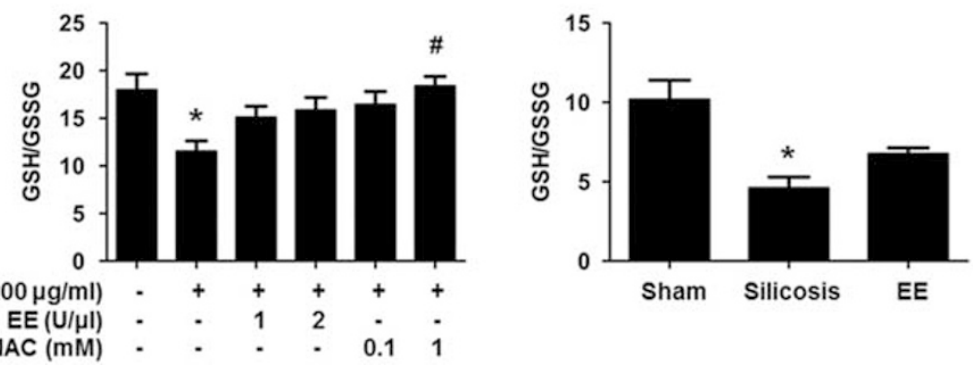
a

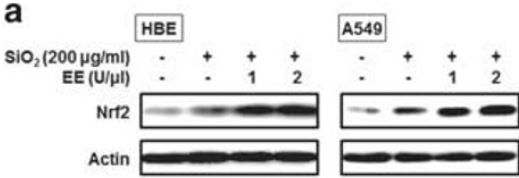

b
sham $\frac{\text { Silicosis }}{7 d}$ 14d 28d $\frac{\text { EE }}{74 d ~ 28 d}$
Actin

e

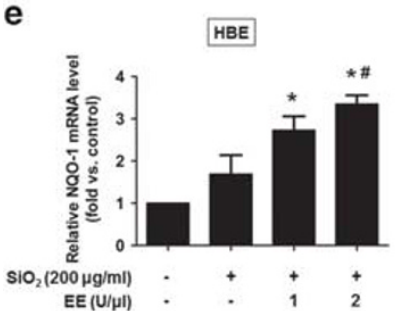

g

g

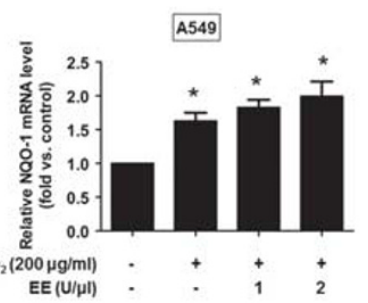

i

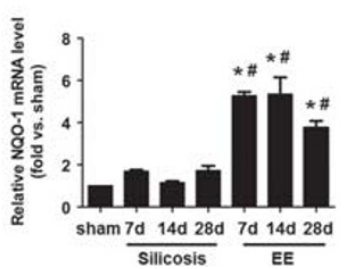

f

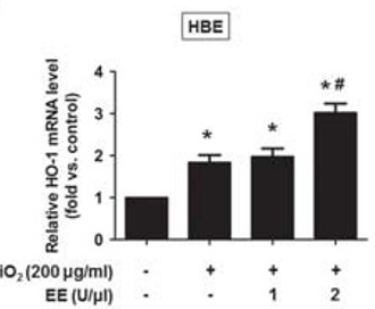

h

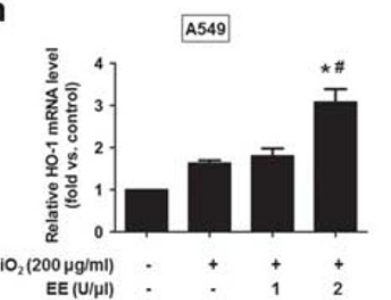

j

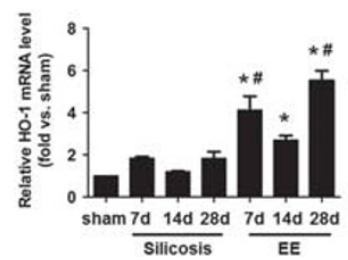

C

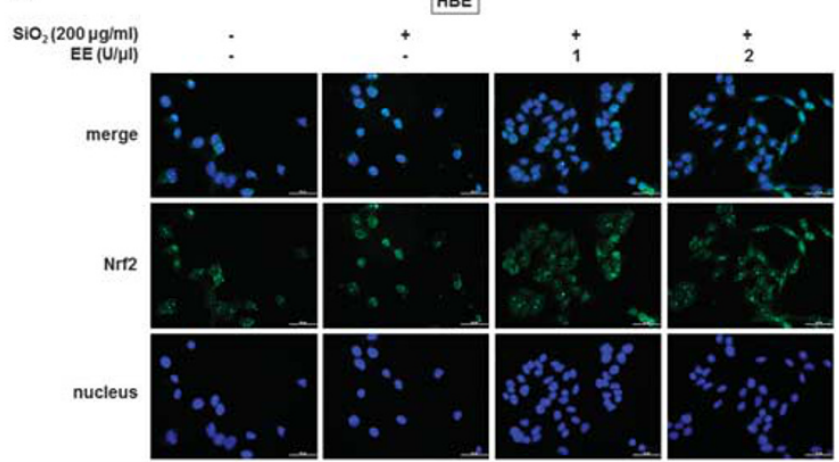

d

$\mathrm{SiO}_{2}(200 \mu \mathrm{g} / \mathrm{ml})$

EE (U/pl)
merge
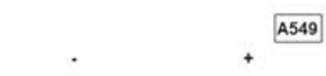

(1)

$+$
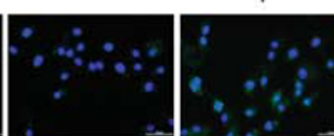

$\stackrel{+}{2}$

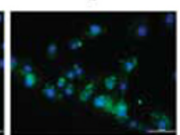

N+12
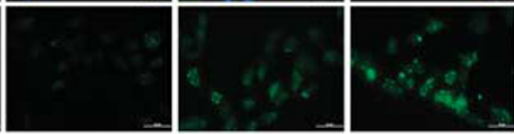

nucleus
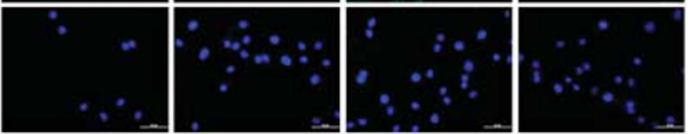

Figure 10 EE activates Nrf2 pathway in vivo and in vitro. Animals and treatments are as described under Materials and Methods. HBE and A549 cells were cultured with EE $(1$ or $2 \mathrm{U} / \mu \mathrm{l})$ for $24 \mathrm{~h}$ under $\mathrm{SiO}_{2}(200 \mu \mathrm{g} / \mathrm{ml})$ stimulation. (a) Western blot analysis of the expression levels of Nrf2 in $\mathrm{HBE}$ and A549 cells. (b) Western blot analysis of Nrf2 in lung tissues of mice from sham, silicosis, and EE groups on days 7, 14, and 28 after induction of fibrosis. (c, d) Effects of EE on the nuclear translocation of Nrf2 in HBE (c) and A549 (d) cells by immunofluorescence. Cells were fixed and labeled for Nrf2 (green) and DNA (blue). (e, f) The mRNA levels of NQO-1 (e) and HO-1 (f) in HBE cells. Quantitative results are presented as mean \pm SD from three independent experiments by qRT-PCR. ${ }^{*} P<0.05$ compared with the control group; ${ }^{\#} P<0.05$ compared with the $\mathrm{SiO}_{2}$ group. ( $\left.\mathbf{g}, \mathbf{h}\right)$ The mRNA levels of NQO-1 (g) and HO-1 (h) in A549 cells. Quantitative results are presented as mean \pm SD from three independent experiments by qRT-PCR. ${ }^{*} P<0.05$ compared with the control group; ${ }^{"} P<0.05$ compared with the $\mathrm{SiO}_{2}$ group. (i, j) The mRNA levels of NQO-1 (i) and HO-1 (j) in lung tissues of mice from sham, silicosis, and EE groups on days 7, 14, and 28 after induction of fibrosis determined by qRT-PCR. ${ }^{*} P<0.05$ compared with the sham group; ${ }^{\#} P<0.05$ compared with the silicosis group at the corresponding time point.

Figure 9 Effects of EE on ROS, TSOD, MDA, and GSH/GSSG levels induced by $\mathrm{SiO}_{2}$. Animals and treatments are as described under Materials and Methods. HBE and A549 cells were cultured with EE (1 or $2 \mathrm{U} / \mu \mathrm{l})$ or NAC $(0.1$ or $1 \mathrm{mM})$ for $24 \mathrm{~h}$ under $\mathrm{SiO}_{2}(200 \mu \mathrm{g} / \mathrm{ml})$ stimulation. (a-c) EE reduced $\mathrm{SiO}_{2}$-induced ROS production in HBE and A549 cells. Intracellular ROS level was evaluated by the oxidation of DCFH to DCF using a fluorescence microscope. Representative images are shown (magnification, 400x; a). Quantitative results for DCF fluorescence intensity are presented as mean \pm SD of the images' mean optical density from three independent experiments in HBE (b) and A549 (c) cells, respectively, using Image J software (http://imagej. nih.gov/ij/). ${ }^{*} P<0.05$ compared with the control group; ${ }^{*} P<0.05$ compared with the $\mathrm{SiO}_{2}$ group. (d, e) Quantitative results of TSOD, MDA, and GSH/ GSSG presented as mean \pm SD from three independent experiments in HBE (d) and A549 (e) cells. ${ }^{*} P<0.05$ compared with the control group; ${ }^{\#} P<0.05$ compared with the $\mathrm{SiO}_{2}$ group. (f) Quantitative results of TSOD $(n=5), \operatorname{MDA}(n=5)$, and GSH/GSSG $(n=3)$ presented as mean \pm SD in the serum of mice on day 7 after induction of fibrosis. ${ }^{*} P<0.05$ compared with the sham group; ${ }^{\#} P<0.05$ compared with the silicosis group at the corresponding time point. 
a
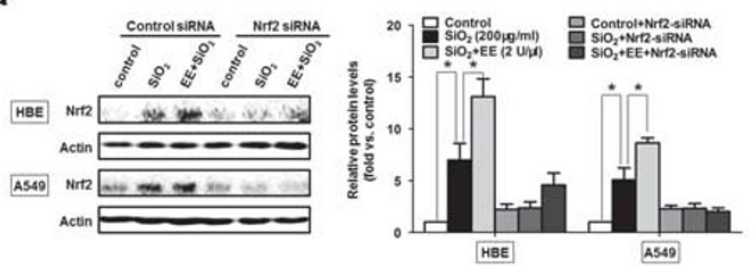

b

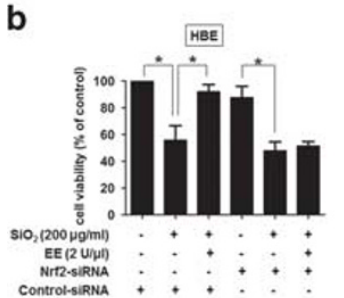

C

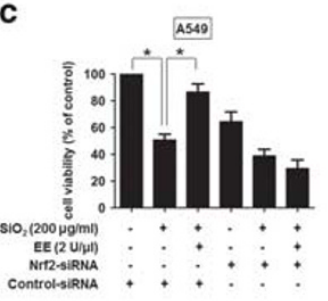

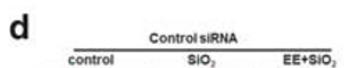

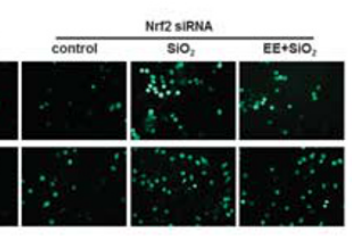

e

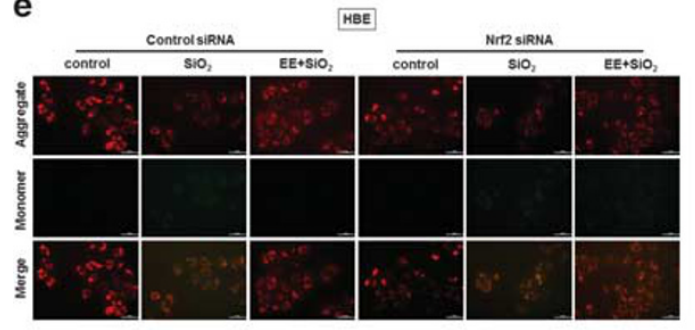

f

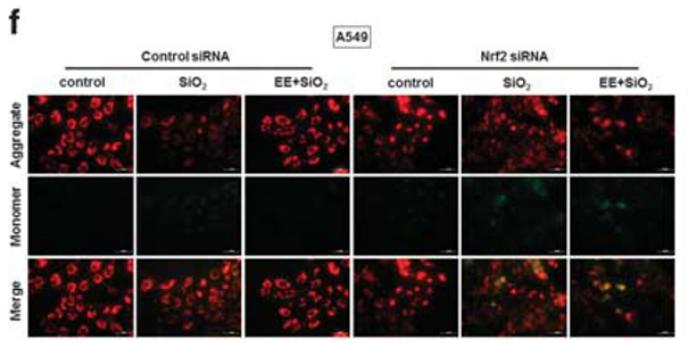

g

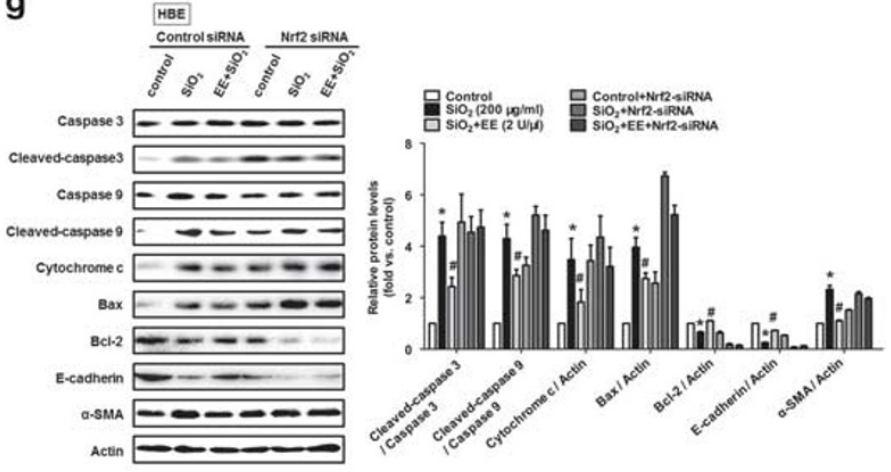

h AS49

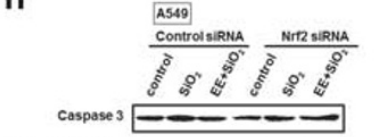

Cleaved-caspases
Caspase 9

Bax $-1-\cdots$

Bct2 ----

E-cadnern

a.SMA $-\ldots$

Actin $-\infty-0-1$

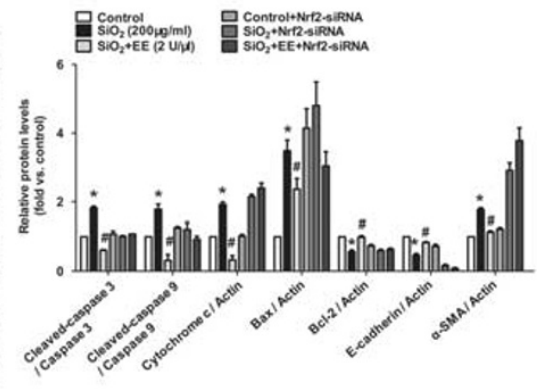

Figure $11 \mathrm{Nrf2}$ mediates the anti-fibrosis effects of EE. $\mathrm{HBE}$ and A549 cells were cultured with $\mathrm{EE}(2 \mathrm{U} / \mu \mathrm{l})$ for $24 \mathrm{~h}$ under $\mathrm{SiO}_{2}(200 \mu \mathrm{g} / \mathrm{ml}) \mathrm{stimulation}$ with control-siRNA or Nrf2-siRNA. (a) Effects of Nrf2 inactivation by RNA interference on Nrf2 expression by western blot in HBE and A549 cells (left). Quantitative results are presented as mean \pm SD of the signal's optical density from three independent experiments (right). ${ }^{*} P<0.05$ within the two groups. (b, c) Effects of Nrf2 inactivation by RNA interference on cell viability in HBE (b) and A549 (c) cells measured by CCK8 assay. ${ }^{*} P<0.05$ within the two groups. (d) Effects of Nrf2 inactivation by RNA interference on ROS level in HBE and A549 cells by DCFH probe. Representative images are shown (magnification, 200x). (e, f) Effects of Nrf2 inactivation by RNA interference on MMP in HBE (e) and A549 (f) cells evaluated by JC-1 staining. Representative images are shown (magnification, 400x). (g) Effects of Nrf2 inactivation by RNA interference on the expressions of caspase 3/9, cleavedcaspase 3/9, cytochrome $c$, Bax, Bcl-2, E-cadherin, and a-SMA in HBE cells by western blot (left). Quantitative results are presented as mean \pm SD of the signal's optical density from three independent experiments (right). ${ }^{*} P<0.05$ compared with the control group; ${ }^{\#} P<0.05$ compared with the $\mathrm{SiO}_{2}$ group. (h) Effects of Nrf2 inactivation by RNA interference on the expressions of caspase 3/9, cleaved-caspase 3/9, cytochrome c, Bax, Bcl-2, E-cadherin, and aSMA in A549 cells by western blot (left). Quantitative results are presented as mean \pm SD of the signal's optical density from three independent experiments (right). ${ }^{*} P<0.05$ compared with the control group; ${ }^{\#} P<0.05$ compared with the $\mathrm{SiO}_{2}$ group.

The effect of Nrf2 on the regulation of mitochondrial apoptotic pathway and EMT by $\mathrm{SiO}_{2}$ and $\mathrm{EE}$ was examined in HBE and A549 cells transfected with control or Nrf2 siRNA. $\mathrm{SiO}_{2}$ induced activation of caspase $9 / 3$, expression of cytochrome $c$ and Bax, and inhibited Bcl-2 expression, and the deleterious effects were higher in Nrf2 KO cells (Figure $11 \mathrm{~g}$ and $\mathrm{h})$. EE $(2 \mathrm{U} / \mu \mathrm{l})$ blocked pro-apoptotic molecules induction and anti-apoptotic protein inhibition by $\mathrm{SiO}_{2}$ in 
WT but not Nrf2 KO cells of HBE and A549 (Figure 11g and h). Thus, Nrf2 is required for EE to block induction of mitochondrial apoptotic pathway by $\mathrm{SiO}_{2}$ in $\mathrm{HBE}$ and A549 cells.

$\mathrm{SiO}_{2}(200 \mu \mathrm{g} / \mathrm{ml})$ induced EMT both in WT and Nrf2 KO cells as evidenced by marked increase in the synthesis of $\alpha$ SMA and the decrease in E-cadherin (Figure 11g and h). EE $(2 \mathrm{U} / \mu \mathrm{l})$ markedly inhibited induction of $\alpha$-SMA and downregulation of E-cadherin by $\mathrm{SiO}_{2}$ in WT but not Nrf2 $\mathrm{KO}$ cells of $\mathrm{HBE}$ and A549 (Figure 11g and h). Therefore, Nrf2 is required for the suppression of $\mathrm{SiO}_{2}$-induced EMT by EE.

\section{DISCUSSION}

In ancient China and even now, earthworms have been considered a delicacy in Guangdong provinces. Furthermore, they are widely consumed for their nutritional contents including amino acids, minerals, fatty acids, and trace elements in New Zealand. ${ }^{25,26}$ In addition to food sources, few people realize the earthworm's association with medicine as early as $1340 \mathrm{AD},{ }^{27}$ and practiced using to treat smallpox, rheumatism, bladder stones, jaundice, alopecia, and other ailments in Asia, Africa, and North America. ${ }^{26}$ In this study, we used NAC mainly to illustrate the intervention effect of antioxidant property of EE against silicosis. However, in recent years, studies have found that NAC has only modest benefit in patients with IPF. Nonetheless, EE has several significant advantages that encourage us to predict that $\mathrm{EE}$ will be effective in silicosis translational effect: (1) EE contains a variety of active ingredients, including polyphenols, fibrinolytic enzyme, growth factors, and so on. Therefore, in addition to the antioxidant pathway, EE can also have a role through other pathways, which need further research; (2) EE has a group of proteolytic enzymes with molecular weights from 25 to $32 \mathrm{kDa}$ that include plasminogen activator and plasmin. ${ }^{28}$ EE has the profound advantage of not causing hemorrhage due to excessive fibrinolysis because it shows thrombolytic activity only in the presence of fibrin. EE capsule has been empirically used in the treatment of stroke and cardiovascular disease for a long period without any serious side effects or adverse events in China. ${ }^{13,29,30}$ Thus, EE has more advantages than a newfound or recently synthesized compound, which needs a very long time and heavy cost to test and evaluate for safety in clinical use. Studies on the pharmacology and mechanisms of EE have been performed in diabetes, diabetic nephropathy, injured peripheral nerves, and granulomatous disease. ${ }^{15,31-33}$ In this study, we investigated the potential efficacy and mechanisms of EE in the treatment of $\mathrm{SiO}_{2}$-induced lung fibrosis.

Lung injury caused by $\mathrm{SiO}_{2}$ is followed by inflammatory events where damaged alveolar epithelium and other resident cells release various cytokines, inflammatory mediators, proteases, and ROS. ${ }^{5}$ These factors could promote the recruitment of inflammatory cells and subsequently result in aberrant fibro-proliferation and collagen production in the lung tissue. Our data showed that EE treatment reduced total cells, macrophages, neutrophils, and lymphocytes in BALF after $\mathrm{SiO}_{2}$ instillation. In addition, after EE administration, the pathological alterations in the lung tissues caused by $\mathrm{SiO}_{2}$ were relieved. Furthermore, EE diminished fibrosis score in mice of silicosis. These data indicate that EE is capable of inhibiting $\mathrm{SiO}_{2}$-induced pulmonary inflammation and fibrosis in mice. Recently, micro-CT has become a useful and effective imaging tool to illustrate lung diseases, including pulmonary fibrosis in small animals, and good images can be obtained without sacrificing the animals. ${ }^{34}$ It has been reported that findings of lung fibrosis on micro-CT imaging were strongly correlated with the pathologic scores of lung fibrosis. ${ }^{35}$ In the current study, EE improves the structure and function of lungs in $\mathrm{SiO}_{2}$-induced pulmonary fibrosis in mice based on micro-CT of lungs and histopathologic confirmations. Next, two cell lines (HBE and A549) were used for uncovering the possible mechanisms of EE's protective effects on $\mathrm{SiO}_{2}$-induced pulmonary fibrosis. As cancer cells, A549 cells own the characteristics of tumor cells and have certain differences with normal alveolar epithelial cells. However, normal human AT II cells in vitro could not continuously be passaged, and would differentiate into type I alveolar epithelial cells in a short period of time. In addition, isolating a strain of epithelial cells almost need a lung tissue due to the difficult separation technology. Therefore, we use A549 cell line to replace human alveolar epithelial cell like other studies.

Apoptosis of lung epithelial cell is increasingly being recognized as a critical event that initiates and propagates fibrosis in lung parenchyma. ${ }^{6}$ When the degree of epithelial cell injury is mild, AT II cells are capable of self-renewal, proliferate, migration, and re-epithelialization. In the most severely damaged alveolar epithelium, the denuded basement membrane is covered by proliferating AT II cells, and there is an apoptosis in AT II cells with massive infiltration by fibroblasts and myofibroblasts, leading to an abnormal wound healing pathway, and finally excessive deposition of extracellular matrix around the damaged epithelium. ${ }^{36}$ Recent evidence reported that caspase inhibitors ${ }^{37}$ or the genetic deletion of apoptosis signaling molecules ${ }^{38}$ blocked fibrogenesis. In line, in the model of bleomycin-induced pulmonary fibrosis, intratracheal instillation of a purified population of syngeneic AT II cells was sufficient to block fibrotic lung remodeling. ${ }^{39}$ Ineffective epithelial cell repair and increased cell apoptosis can lead to aberrant fibroblastic responses and end-stage fibrosis. The present in vitro study observed that $\mathrm{EE}$ promoted cell proliferation and protected against cell apoptosis induced by a $\mathrm{SiO}_{2}$ challenge in $\mathrm{HBE}$ and $\mathrm{A} 549$ cells. It has therefore been hypothesized that EE may attenuate lung fibrosis in vivo by the rescue of injured lung epithelial cells. A possible mechanism explaining the EEinduced reduction in lung epithelial cell apoptosis is the component of various growth factors. ${ }^{26}$ It may also be speculated that apoptosis of AT II cells is mediated by ROS, which are involved in $\mathrm{SiO}_{2}$-induced lung injury. ${ }^{40,41}$ It has been shown that $\mathrm{EE}$ has anti-oxidative activity; therefore $\mathrm{EE}$ 
may inhibit the apoptosis of AT II cells and pulmonary fibrosis by an antioxidant effect.

Mitochondria have many pivotal functions, such as being the site of election transfer chain, oxidative phosphorylation, and ATP synthesis, and mainly participate in cell apoptosis regulation. ${ }^{42}$ They are not only major sources of ROS generation, but also sensitive targets for oxygen radical. ${ }^{43}$ High ROS levels in cells lead to depolarization of MMP and the loss of MMP subsequently triggers cytochrome $c$ release from mitochondria to the cytosol, which is essential for the activation of the caspase cascade. ${ }^{44}$ Furthermore, the release of cytochrome $c$ impacts functions of respiratory chain complexes III and IV, which interrupt cellular electron flow, subsequently suppressing ATP generation and leading to ROS overproduction. It has been reported that $\mathrm{SiO}_{2}$ could initiate apoptosis in response to ROS, leading to mitochondrial dysfunction. ${ }^{5}$ In our study, EE restrained the loss of MMP and the decreased ATP level induced by $\mathrm{SiO}_{2}$ in $\mathrm{HBE}$ and A549 cells, which indicated that $\mathrm{EE}$ protected lung epithelial cells against $\mathrm{SiO}_{2}$-induced mitochondrial dysfunction. Moreover, here we showed that $\mathrm{SiO}_{2}$ significantly increased cytochrome $c$ release, the activation of caspase 9 and caspase 3 both in vivo and in vitro. However, these effects were all inhibited by $\mathrm{EE}$ in vivo and in vitro.

The mitochondrial apoptosis pathway is known to be regulated by members of the Bcl-2 family, which includes both anti-apoptotic (Bcl-2 and $\mathrm{Bcl}-\mathrm{xl}$ ) and pro-apoptotic (Bad and Bax) proteins. ${ }^{45}$ Our results found that $\mathrm{EE}$ prevented the expression of Bax but increased the expression of Bcl-2 in vivo and in vitro. Previous studies showed that $\mathrm{EE}$ remarkably inhibited mitochondria apoptotic pathways in the hippocampus of young hamsters ${ }^{19}$ and hearts of rats ${ }^{18}$ exposed to second-hand tobacco smoke. Ji et al ${ }^{17}$ suggested that the anti-apoptotic effect of EE was due to the activation of JAK1/STAT1 pathway in human umbilical vein endothelial cell and ischemic cerebral tissues. These findings demonstrate that the effects of EE against lung fibrosis may be mediated through the inhibition of mitochondrial dependent apoptosis in lung epithelial cell.

In response to a tissue injury, myofibroblasts are activated and localize to the sites of the damage, forming so-called fibroblastic foci that underlie sites of unresolved epithelial injury, to contribute to the wound healing process. ${ }^{6}$ In lung tissue from interstitial pulmonary fibrosis patients, $\alpha$-SMApositive, collagen-secreting myofibroblasts have been shown to arise from the differentiation of local epithelial progenitors via EMT. ${ }^{46,47}$ Changes consistent with EMT have been observed within alveolar epithelium in animal models of silicosis. ${ }^{48}$ In this study, we found that EE inhibited EMT in vivo and in vitro. The epithelium is not only the primary site of lung damage but also the primary site of releases of cytokines facilitating inflammatory and fibrotic processes. AT II has been demonstrated to be a major source of pro-fibrotic TGF- $\beta 1$, which has been shown to stimulate both EMT in alveolar and bronchial epithelial cells and the synthesis of extracellular matrix proteins by myofibroblasts, ${ }^{49-51}$ via its Smad-dependent signaling pathway. Recent studies show that induction of PAI-1 during fibrosing lung injury leads to EMT in AT II cells. ${ }^{52}$ IL-1 $\beta$ induces EMT and myofibroblast activation through a TGF- $\beta 1$-mediated mechanism, ${ }^{53}$ acting as a potent upstream driver of fibrosis. Data from our group found an increase in the expression of TGF- $\beta 1$, PAI- 1 , and IL- $1 \beta$ after $\mathrm{SiO}_{2}$ stimulation in $\mathrm{HBE}$ and $\mathrm{A} 549$ cells, which was inhibited significantly by EE treatment. Moreover, our in vivo results were consistent with in vitro data. Therefore, the effects of EE against silicosis may be also associated with the inhibition of cytokines production and EMT induced by $\mathrm{SiO}_{2}$.

Accumulating evidence suggests that oxidative stress has a vital role in the development of fibrotic lung disease. For example, the results by Peluso et al $l^{54}$ have shown that occupationally exposed to $\mathrm{SiO}_{2}$ dust induces oxidatively damaged DNA in the nasal epithelium of workers. In the present study, we provided several lines of evidence that EE treatment alleviated $\mathrm{SiO}_{2}$-induced pulmonary oxidative stress. EE treatment decreased MDA level, whereas it increased antioxidative GSH and activity of antioxidant enzyme SOD in serum obtained from $\mathrm{SiO}_{2}$-injured mice and in lung epithelial cell treated with $\mathrm{SiO}_{2}$. Consistent with our results, previous studies have reported that EE alleviates oxidative stress. ${ }^{14,16} \mathrm{It}$ has been well established that the increased level of ROS in lung epithelium under pathological conditions is a main trigger leading to epithelial injury involved apoptosis ${ }^{55}$ and EMT. ${ }^{56}$ Thus, together with the effects of antioxidant NAC on apoptosis and EMT induced by $\mathrm{SiO}_{2}$ in lung epithelial cell, we speculate that the underlying mechanism of $\mathrm{EE}$ against apoptosis and EMT induced by $\mathrm{SiO}_{2}$ may be increasing antioxidant defend systems.

To maintain a proper redox balance, the respiratory system is endowed with an antioxidant defense system consisting of endogenous antioxidant enzymes. The expression of most antioxidant enzymes is tightly controlled by the antioxidant response element and is activated by $\mathrm{Nrf2}$, a redox-sensitive transcription factor. ${ }^{11}$ In the lungs, the dysfunction of cellular defense systems resulting from Nrf2 removal has been proven to increase animals' susceptibility to acute lung injury caused by hyperoxia. ${ }^{57}$ Previous studies have highlighted the protective effects of pharmacological activation of Nrf2 in reducing oxidative stress, inflammation and increasing levels of tight junction proteins zonula occludens-1 and E-cadherin in lung epithelium. ${ }^{58} \mathrm{Nrf} 2$ inducers have been discovered and used in model systems of oxidant-induced lung diseases, and data suggest a potential for clinical interventions. ${ }^{59} \mathrm{~A}$ previous study indicated that $\mathrm{SiO}_{2}$ could significantly cause the accumulation of ROS and MDA as well as activate Nrf2 and its downstream protein $\mathrm{Trx}$ in the early exposure to $\mathrm{SiO}_{2} \cdot{ }^{60}$ Consistent with this result, we also found that $\mathrm{SiO}_{2}$ exposure mildly induced Nrf2 expression in lung tissues and lung epithelial cells. In addition, our results demonstrated that $\mathrm{EE}$ further increased Nrf2 expression and promoted Nrf2 nuclear 
accumulation and transcriptional activity in HBE and A549 cells. Furthermore, knockout of Nrf2 by siRNA partly blocked the anti-fibrotic effects of EE. On the basis of this knowledge, we demonstate that $\mathrm{EE}$ inhibits oxidative stress partly through $\mathrm{Nrf2}$ activation, and therefore alleviating $\mathrm{SiO}_{2}$-induced apoptosis and EMT of lung epithelial cells.

To our knowledge, the present study was the first to show that EE is effective in reducing apoptosis and EMT of lung epithelial cell induced by $\mathrm{SiO}_{2}$, resulting in fewer lung injuries, lower fibrosis scores, and improved lung structure by their significant antioxidant capacity. These effects were partly dependent of the activation of Nrf2. EE may provide a novel approach for the treatment of silicosis. However, there may be two main issues, which need to be investigated in future studies: (1) the pathway through which Nrf2 is regulated during EE treatment; (2) the other mechanisms of EE in mitigating $\mathrm{SiO}_{2}$-induced lung fibrosis, such as the activation of fibrinolytic system as well as the inhibition of coagulation system.

Supplementary Information accompanies the paper on the Laboratory Investigation website (http://www.laboratoryinvestigation.org)

\section{ACKNOWLEDGMENTS}

This study was supported by the Priority Academic Program Development of Jiangsu Higher Education Institutions (PAPD). The funders had no roles in the study design, the data collection and analysis, the decision to publish, or the preparation of the manuscript.

\section{DISCLOSURE/CONFLICT OF INTEREST}

The authors declare no conflict of interest.

1. Leung CC, Yu IT, Chen W. Silicosis. Lancet 2012;379:2008-2018.

2. Jindal SK. Silicosis in India: past and present. Curr Opin Pulm Med 2013;19:163-168.

3. Rimal B, Greenberg AK, Rom WN. Basic pathogenetic mechanisms in silicosis: current understanding. Curr Opin Pulm Med 2015;11:169-173.

4. Richeldi L, Collard HR, du Bois RM, et al. Mapping the future for pulmonary fibrosis: report from the 17th International Colloquium on Lung and Airway Fibrosis. Eur Respir J 2013;42:230-238.

5. Fubini B, Hubbard A. Reactive oxygen species (ROS) and reactive nitrogen species (RNS) generation by silica in inflammation and fibrosis. Free Radic Biol Med 2003;34:1507-1516.

6. Borensztajn K, Crestani B, Kolb M. Idiopathic pulmonary fibrosis: from epithelial injury to biomarkers-insights from the bench side. Respiration 2013;86:441-452.

7. Castranova V, Vallyathan V. Silicosis and coal workers' pneumoconiosis. Environ Health Perspect 2000;108:675-684.

8. Cheresh P, Kim SJ, Tulasiram S, et al. Oxidative stress and pulmonary fibrosis. Biochim Biophys Acta 2013;1832:1028-1040.

9. Kinnula VL, Myllarniemi M. Oxidant-antioxidant imbalance as a potential contributor to the progression of human pulmonary fibrosis. Antioxid Redox Signal 2008;10:727-738.

10. Kirkham P, Rahman I. Oxidative stress in asthma and COPD: antioxidants as a therapeutic strategy. Pharmacol Ther 2006;111: 476-494.

11. Kaspar JW, Niture SK, Jaiswal AK. Nrf2:INrf2 (Keap1) signaling in oxidative stress. Free Radic Biol Med 2009;47:1304-1309.

12. Mihara $\mathrm{H}$, Sumi $\mathrm{H}$, Yoneta $\mathrm{T}$, et al. A novel fibrinolytic enzyme extracted from the earthworm, Lumbricus rubellus. Jpn J Physiol 1991;41: 461-472.

13. Jin $L$, Jin $H$, Zhang $G$, et al. Changes in coagulation and tissue plasminogen activator after the treatment of cerebral infarction with lumbrokinase. Clin Hemorheol Microcirc 2000;23:213-218.
14. Balamurugan M, Parthasarathi K, Cooper EL, et al. Earthworm paste (Lampito mauritii, Kinberg) alters inflammatory, oxidative, haematological and serum biochemical indices of inflamed rat. Eur Rev Med Pharmacol Sci 2007;11:77-90.

15. Balamurugan M, Parthasarathi K, Cooper EL, et al. Anti-inflammatory and anti-pyretic activities of earthworm extract-Lampito mauritii (Kinberg). J Ethnopharmacol 2009;121:330-332.

16. Prakash $M$, Balamurugan $M$, Parthasarathi $K$, et al. Anti-ulceral and antioxidative properties of "earthworm paste" of Lampito mauritii (Kinberg) on Rattus norvegicus. Eur Rev Med Pharmacol Sci 2007:11:9-15.

17. Ji H, Wang L, Bi H, et al. Mechanisms of lumbrokinase in protection of cerebral ischemia. Eur J Pharmacol 2008;590:281-289.

18. Liao HE, Lai CH, Ho TJ, et al. Cardio protective effects of lumbrokinase and dilong on second-hand smoke-induced apoptotic signaling in the heart of a rat model. Chin J Physiol 2015;58:188-196.

19. Huang $\mathrm{CY}$, Kuo WW, Liao HE, et al. Lumbrokinase attenuates sidestream-smoke-induced apoptosis and autophagy in young hamster hippocampus: correlated with eNOS induction and NFkappaB/iNOS/ COX-2 signaling suppression. Chem Res Toxicol 2013:26:654-661.

20. Han $\mathrm{CK}$, Kuo WW, Shen $\mathrm{CY}$, et al. Dilong prevents the high-KCl cardioplegic solution administration-induced apoptosis in H9c2 cardiomyoblast cells mediated by MEK. Am J Chin Med 2014;42:1507-1519.

21. Sharawy MH, El-Agamy DS, Shalaby AA, et al. Protective effects of methyl palmitate against silica-induced pulmonary fibrosis in rats. Int Immunopharmacol 2013;16:191-198.

22. Nie $L$, Xiang $R$, Zhou $W$, et al. Attenuation of acute lung inflammation induced by cigarette smoke in CXCR3 knockout mice. Respir Res 2008;9:82

23. De Langhe E, Vande Velde G, Hostens J, et al. Quantification of lung fibrosis and emphysema in mice using automated micro-computed tomography. PLoS One 2012;7:e43123.

24. Zhang L, He YL, Li QZ, et al. N-acetylcysteine alleviated silica-induced lung fibrosis in rats by down-regulation of ROS and mitochondrial apoptosis signaling. Toxicol Mech Methods 2014;24:212-219.

25. Paoletti MG, Buscardo E, VanderJagt DJ, et al. Nutrient content of earthworms consumed by Ye'Kuana Amerindians of the Alto Orinoco of Venezuela. Proc Biol Sci 2003:270:249-257.

26. Cooper EL, Balamurugan $\mathrm{M}$, Huang $\mathrm{CY}$, et al. Earthworms dilong: ancient, inexpensive, noncontroversial models may help clarify approaches to integrated medicine emphasizing neuroimmune systems. Evid Based Complement Alternat Med 2012;2012:11.

27. Reynolds JW, Reynolds WM. Earthworms in medicine. Am J Nurs 1972;72:1273.

28. Nakajima N, Mihara $\mathrm{H}$, Sumi $\mathrm{H}$. Characterization of potent fibrinolytic enzymes in earthworm, Lumbricus rubellus. Biosci Biotechnol Biochem 1993:57:1726-1730.

29. Yan D. Small-dose aspirin plus lumbrukinase in improving neurological function of patients with acute cerebral infarction. Chin J Clin Rehabil 2006;6.

30. Yu J. Study of lumbrukinase with safflower yellow for acute cerebral infarction: a report of 50 cases. Jiangxi Zhong Yi Yao 2010;41:39-40.

31. Wei $S$, Yin $X$, Kou Y, et al. Lumbricus extract promotes the regeneration of injured peripheral nerve in rats. J Ethnopharmacol 2009;123:51-54.

32. Liu LF, Wen XY, Xu MW. Effects of zhenqing recipe and earthworm on the expressions of transforming growth factor-beta 1 and plasminogen activator inhibitor 1 in renal tissues of type 2 diabetic rats. Zhongguo Zhong Xi Yi Jie He Za Zhi 2011;31:967-972.

33. Sun $\mathrm{H}, \mathrm{Ge} N$, Shao $M$, et al. Lumbrokinase attenuates diabetic nephropathy through regulating extracellular matrix degradation in Streptozotocin-induced diabetic rats. Diabetes Res Clin Pract 2013;100: $85-95$.

34. Jin GY, Bok SM, Han YM, et al. Effectiveness of rosiglitazone on bleomycin-induced lung fibrosis: assessed by micro-computed tomography and pathologic scores. Eur J Radiol 2012;81:1901-1906.

35. Choi EJ, Jin GY, Bok SM, et al. Serial micro-CT assessment of the therapeutic effects of rosiglitazone in a bleomycin-induced lung fibrosis mouse model. Korean J Radiol 2014;15:448-455.

36. Li H. The alveolar epithelium and pulmonary fibrosis. J Epithel Biol Pharmacol 2009;2:30-35.

37. Wang $R$, Ibarra-Sunga $O$, Verlinski $L$, et al. Abrogation of bleomycininduced epithelial apoptosis and lung fibrosis by captopril or by a caspase inhibitor. Am J Physiol Lung Cell Mol Physiol 2000;279: L143-L151. 
38. Budinger GR, Mutlu GM, Eisenbart J, et al. Proapoptotic Bid is required for pulmonary fibrosis. Proc Natl Acad Sci U S A 2006;103: 4604-4609.

39. Serrano-Mollar A, Nacher M, Gay-Jordi G, et al. Intratracheal transplantation of alveolar type II cells reverses bleomycin-induced lung fibrosis. Am J Respir Crit Care Med 2007;176:1261-1268.

40. Santarelli L, Recchioni R, Moroni F, et al. Crystalline silica induces apoptosis in human endothelial cells in vitro. Cell Biol Toxicol 2004;20: 97-108.

41. Antognelli C, Gambelunghe A, Muzi G, et al. Peroxynitrite-mediated glyoxalase I epigenetic inhibition drives apoptosis in airway epithelial cells exposed to crystalline silica via a novel mechanism involving argpyrimidine-modified Hsp70, JNK, and NF-kappaB. Free Radic Biol Med 2015;84:128-141.

42. Desagher S, Martinou JC. Mitochondria as the central control point of apoptosis. Trends Cell Biol 2000;10:369-377.

43. Lee $\mathrm{HC}$, Wei $\mathrm{YH}$. Mitochondrial role in life and death of the cell. J Biomed Sci 2000;7:2-15.

44. Huttemann $M$, Pecina $P$, Rainbolt $M$, et al. The multiple functions of cytochrome $c$ and their regulation in life and death decisions of the mammalian cell: from respiration to apoptosis. Mitochondrion 2011;11: 369-381.

45. Burlacu A. Regulation of apoptosis by $\mathrm{Bcl}-2$ family proteins. J Cell Mol Med 2003;7:249-257.

46. Richeldi L, du Bois RM. Pirfenidone in idiopathic pulmonary fibrosis: the CAPACITY program. Expert Rev Respir Med 2011;5: 473-481.

47. Willis $B C$, duBois RM, Borok Z. Epithelial origin of myofibroblasts during fibrosis in the lung. Proc Am Thorac Soc 2006;3:377-382.

48. Wang Y, Yang G, Zhu Z, et al. Effect of bone morphogenic protein-7 on the expression of epithelial-mesenchymal transition markers in silicosis model. Exp Mol Pathol 2015;98:393-402.

49. Kasai H, Allen JT, Mason RM, et al. TGF-beta1 induces human alveolar epithelial to mesenchymal cell transition (EMT). Respir Res 2005;6:56.
50. Camara J, Jarai G. Epithelial-mesenchymal transition in primary human bronchial epithelial cells is Smad-dependent and enhanced by fibronectin and TNF-alpha. Fibrogenesis Tissue Repair 2010;3:2.

51. Nonaka M, Pawankar R, Fukumoto A, et al. Heterogeneous response of nasal and lung fibroblasts to transforming growth factor-beta 1. Clin Exp Allergy 2008;38:812-821.

52. Marudamuthu AS, Bhandary YP, Shetty SK, et al. Role of the urokinasefibrinolytic system in epithelial-mesenchymal transition during lung injury. Am J Pathol 2015;185:55-68.

53. Fan JM, Huang $X R, N g ~ Y Y$, et al. Interleukin-1 induces tubular epithelial-myofibroblast transdifferentiation through a transforming growth factor-beta1-dependent mechanism in vitro. Am J Kidney Dis 2001;37:820-831.

54. Peluso ME, Munnia A, Giese RW, et al. Oxidatively damaged DNA in the nasal epithelium of workers occupationally exposed to silica dust in Tuscany region, Italy. Mutagenesis 2015;30:519-525.

55. Cui J, Zhao H, Wang $\mathrm{C}$, et al. Dexmedetomidine attenuates oxidative stress induced lung alveolar epithelial cell apoptosis in vitro. Oxid Med Cell Longev 2015;2015:358396.

56. Gorowiec MR, Borthwick LA, Parker SM, et al. Free radical generation induces epithelial-to-mesenchymal transition in lung epithelium via a TGF-beta1-dependent mechanism. Free Radic Biol Med 2012;52: 1024-1032.

57. Reddy NM, Potteti HR, Mariani TJ, et al. Conditional deletion of Nrf2 in airway epithelium exacerbates acute lung injury and impairs the resolution of inflammation. Am J Respir Cell Mol Biol 2011;45: 1161-1168.

58. Sussan TE, Gajghate $\mathrm{S}$, Chatterjee $\mathrm{S}$, et al. Nrf2 reduces allergic asthma in mice through enhanced airway epithelial cytoprotective function. Am J Physiol Lung Cell Mol Physiol 2015;309:L27-L36.

59. Cho HY, Kleeberger SR. Noblesse oblige: NRF2 functions in the airways. Am J Respir Cell Mol Biol 2014;50:844-847.

60. Zhu Z, Yang G, Wang Y, et al. Suppression of thioredoxin system contributes to silica-induced oxidative stress and pulmonary fibrogenesis in rats. Toxicol Lett 2013;222:289-294. 